\title{
Article
}

\section{Differential Proteomic Analysis of Astrocytes and Astrocytes-Derived Extracellular Vesicles from Control and Rai Knockout Mice: Insights into the Mechanisms of Neuroprotection}

\author{
Tommaso Montecchi ${ }^{1,+}{ }^{\dagger}$ Enxhi Shaba ${ }^{2,+}+\mathbb{C}$, Domiziana De Tommaso ${ }^{1}$ (D) Fabrizio Di Giuseppe ${ }^{3}$, \\ Stefania Angelucci ${ }^{3}$, Luca Bini ${ }^{2}\left(\mathbb{D}\right.$, Claudia Landi ${ }^{2, *}$, Cosima Tatiana Baldari ${ }^{1, *}$ and Cristina Ulivieri ${ }^{1, *}$ \\ 1 Department of Life Sciences, University of Siena, Via Aldo Moro, 2, 53100 Siena, Italy; \\ tommaso.montecchi@gmail.com (T.M.); detommasodomiziana@gmail.com (D.D.T.) \\ 2 Functional Proteomics Laboratory, Department of Life Sciences, University of Siena, Via Aldo Moro, 2, \\ 53100 Siena, Italy; shaba3@student.unisi.it (E.S.); luca.bini@unisi.it (L.B.) \\ 3 Centre of Advanced Studies and Technoloy, Dentistry and Biotechnology and Proteomics Unit, \\ Department Medical, Oral \& Biotechnological Sciences, "G. d'Annunzio", University of Chieti-Pescara, \\ Via dei Vestini, 31, 66100 Chieti, Italy; f.digiuseppe@unich.it (F.D.G.); s.angelucci@unich.it (S.A.) \\ * Correspondence: landi35@unisi.it (C.L.); cosima.baldari@unisi.it (C.T.B.); cristina.ulivieri@unisi.it (C.U.); \\ Tel.: +39-0577-234937 (C.L.); +39-0577-234400 (C.T.B.); +39-0577-234403 (C.U.) \\ + These authors contributed equally to this work.
}

Citation: Montecchi, T.; Shaba, E.; De Tommaso, D.; Di Giuseppe, F.; Angelucci, S.; Bini, L.; Landi, C.; Baldari, C.T.; Ulivieri, C. Differential Proteomic Analysis of Astrocytes and Astrocytes-Derived Extracellular Vesicles from Control and Rai Knockout Mice: Insights into the Mechanisms of Neuroprotection. Int. J. Mol. Sci. 2021, 22, 7933. https:// doi.org/10.3390/ijms22157933

Academic Editors: Graça Baltazar and Cláudio Roque

Received: 26 May 2021

Accepted: 22 July 2021

Published: 25 July 2021

Publisher's Note: MDPI stays neutral with regard to jurisdictional claims in published maps and institutional affiliations.

Copyright: () 2021 by the authors. Licensee MDPI, Basel, Switzerland. This article is an open access article distributed under the terms and conditions of the Creative Commons Attribution (CC BY) license (https:// creativecommons.org/licenses/by/ $4.0 /)$.
Abstract: Reactive astrocytes are a hallmark of neurodegenerative disease including multiple sclerosis It is widely accepted that astrocytes may adopt alternative phenotypes depending on a combination of environmental cues and intrinsic features in a highly plastic and heterogeneous manner. However, we still lack a full understanding of signals and associated signaling pathways driving astrocyte reaction and of the mechanisms by which they drive disease. We have previously shown in the experimental autoimmune encephalomyelitis mouse model that deficiency of the molecular adaptor Rai reduces disease severity and demyelination. Moreover, using primary mouse astrocytes, we showed that Rai contributes to the generation of a pro-inflammatory central nervous system (CNS) microenvironment through the production of nitric oxide and IL- 6 and by impairing CD39 activity in response to soluble factors released by encephalitogenic $\mathrm{T}$ cells. Here, we investigated the impact of Rai expression on astrocyte function both under basal conditions and in response to IL-17 treatment using a proteomic approach. We found that astrocytes and astrocyte-derived extracellular vesicles contain a set of proteins, to which Rai contributes, that are involved in the regulation of oligodendrocyte differentiation and myelination, nitrogen metabolism, and oxidative stress. The HIF- $1 \alpha$ pathway and cellular energetic metabolism were the most statistically relevant molecular pathways and were related to ENOA and HSP70 dysregulation.

Keywords: astrocytes; molecular adaptor; IL-17; proteomics; extracellular vesicles; HIF-1 $\alpha$

\section{Introduction}

Astrocytes are the predominant cell type in the central nervous system (CNS) which control the homeostasis of the CNS through the regulation of extracellular ion concentration and the secretion of a wide array of soluble factors including neurotrophic factors and neurotransmitters [1]. In addition, similar to other cell types, astrocytes release extracellular vesicles (EVs) under both physiological and pathological conditions which further contribute to shape the CNS microenvironment [2]. As components of the glia limitants and by expressing specialized channel-forming proteins (AQP4, Kir4.1 and Connexin43), astrocytes also regulate the diffusion of soluble factors across the blood brain barrier (BBB) [3]. The recent demonstration that EVs are able to cross the BBB and that astrocytes are the main secretory cells of the CNS [4] further supports the notion that astrocytes are key determinants of brain function. 
It is now widely accepted that astrocyte reaction to CNS insults is heterogeneous and depends on physiological context, type of injury, location in the CNS, and microenvironment. Indeed, when CNS injury or disease occurs, astrocytes react by changing morphological, biochemical, transcriptional, and functional programs as a result of a combination of environmental cues and intrinsic features [5]. The signals and associated signaling pathways that drive astrocyte reaction are at present largely unknown, but a mechanism by which activated microglia through the secretion of IL- $1 \alpha$, TNF, and C1q induces neurotoxic astrocytes has been described [6].

In recent years astrocytes have emerged as crucial modulators of inflammation during multiple sclerosis (MS), a CNS-affecting autoimmune disease, and experimental autoimmune encephalomyelitis (EAE), the mouse model of human MS [7-9]. Relevant to MS, depletion of astrocytes either genetically or following ganciclovir treatment in the EAE animal model resulted in different outcomes depending on the phase of disease. Inhibition of astrocyte reaction worsens the EAE course during the early phase of disease, while in the chronic phase it improves the clinical signs, underscoring the complex and multifaceted role played by these cells in MS [9]. This view of astrocytes as cells able to protect or promote disease depending on the environmental context and disease stage is challenging and supports the rationale to consider astrocytes as targets for the development of therapies for neurodegenerative disease [10]. This has been hampered to date by the lack of information on the molecular mechanisms driving astrocyte reactivity and the fact that astrocytes have been only recently identified as central modulators of neurodegeneration.

At present, the "omics" approaches including proteomics, spatial transcriptomics, and single-cell RNA sequencing represent the gold standard to understand the impact of external stimuli and cell-intrinsic characteristics on astrocyte responses in a given context and to identify specific molecular markers [11,12]. In this context, a seminal report by Wheeler and colleagues identified several subpopulations of astrocytes in EAE mice that differed from those found in healthy mice by single-cell transcriptomic analysis [13]. In particular, a subpopulation of astrocytes characterized by the activation of the pro-inflammatory and neurotoxic pathways such as the unfolding protein response, the activation of NF- $\mathrm{kB}$, and the inducible nitric oxide synthase (iNOS) pathways has been identified as the pathogenic and most expanded subpopulation during EAE [13].

We demonstrated that Rai, a member of the Shc family of protein adaptors that negatively regulates $\mathrm{T}$ cell activation and Th17 cell development [14,15], is expressed in astrocytes where it promotes the production of pro-inflammatory mediators (IL-6, NO) induced by Th17 cells. Interestingly, EAE mice lacking Rai showed amelioration of disease severity characterized by delayed onset, lower clinical score, and reduced demyelination compared with control EAE mice. The reduced degree of demyelination was associated with a reduced activation of astrocytes, supporting the notion that Rai expression in astrocytes is an important determinant in MS immunopathology [16]. We recently demonstrated that the ability of astrocytes lacking Rai to control the pathogenic potential of autoreactive T cells involves the conversion of extracellular ATP to the immunosuppressive molecule adenosine through the enhancement of CD39 ectonucleotidase activity [17]. Moreover, we showed that astrocytes lacking Rai skew towards a neuroprotective phenotype in response to encephalitogenic T cells, both in vitro and in EAE mice [17]. Together, these findings underscore the multifaceted role played by Rai in astrocyte reactivity during EAE, suggesting the possibility that targeting Rai expression in astrocytes may represent a strategy to impact on the course of disease.

Here, we investigated whether Rai has an impact on the astrocyte proteome both in basal conditions and following activation with the pro-inflammatory cytokine IL-17. Additionally, since astrocyte-derived extracellular vesicles (ADEV) play a crucial role in shaping the surrounding microenvironment both in physiological and pathological conditions [2], we investigated whether Rai impinges on the proteome of ADEVs under the same conditions. 


\section{Results}

\subsection{Rai Participates in the Astrocyte Response to IL-17 and IFN $\gamma$ through the Activation of NF- $\kappa B$}

We recently provided evidence that conditioned media from MOG-specific $T$ cells induced the acquisition of a neuroprotective phenotype by astrocytes lacking the molecular adaptor Rai [17]. To determine whether the Th17 signature cytokines, IL-17 and IFN $\gamma$ are responsible for this effect, control and $\mathrm{Rai}^{-/-}$astrocytes were treated with these recombinant cytokines and the expression levels of transcripts known to be upregulated in neuroprotective astrocytes were measured by qRT-PCR. Rai ${ }^{-1-}$ astrocytes showed a significant upregulation of the neuroprotective-specific transcripts Emp1 and S100a10 compared with control astrocytes (Figure 1A), consistent with the results obtained following treatment with conditioned media from MOG-specific T cells [17]. Analysis of the activation status of NF-kB, a key transcription factor in cytokine signaling and a known driver of the proinflammatory response of astrocytes [18], showed that it was completely inhibited in $\mathrm{Rai}^{-/-}$astrocytes both following stimulation with IL-17 and IFN $\gamma$, and in the presence of conditioned media from encephalitogenic T cells (Figure 1B) suggesting that Rai drives the astrocyte response to inflammatory soluble factors secreted by $\mathrm{T}$ cells through the activation of NF-kB. Of note, treatment of control and $\mathrm{Rai}^{-1-}$ astrocytes with known inducers of astrocyte neurotoxicity, namely conditioned medium from LPS-activated microglia or a combination of the microglia-derived soluble factors, IL- $1 \alpha, \mathrm{TNF}$, and C1q [6], resulted in a strong upregulation of the neurotoxic-specific transcripts $\mathrm{C} 3$ not only in control astrocytes as previously reported [6] but also in Rai-deficient astrocytes (Figure 1C). At variance, Rai deletion did not affect the levels of Emp1 and S100a10 mRNA under these conditions (Figure 1C) indicating that Rai is a key participant in the signaling pathway controlling the astrocyte response to $\mathrm{T}$ cells, but not to microglia.

\subsection{Differential Proteome Profile of Control and $\mathrm{Rai}^{-/-}$Astrocytes}

While our data suggest that the $\mathrm{T}$ cell-dependent detrimental astrocyte reaction is supported by Rai (Figure 1 and [16]), whether astrocytes lacking Rai gain some protective functions that contribute to cell-autonomous neuroprotection is unknown. Thus, we investigated the impact of Rai on the homeostatic functions of astrocytes and on the functional changes in response to IL-17, the signature cytokine of Th17 cells responsible for astrogliosis during EAE [19] whose signaling is impaired by Rai deficiency [16], by large scale comparison of the proteome profiles of control and Rai ${ }^{-/-}$astrocytes.

We first determined whether Rai deficiency impacts the homeostatic proteome of astrocytes. Under basal conditions, 2D-Electrophoresis (2DE) and image analysis revealed a mean of 2914 spots per gel. The Kruskall-Wallis test for multiple comparisons and false discovery rate control identified 22 differentially abundant spots in astrocytes of control and $\mathrm{Rai}^{-1-}$ mice. All 22 electrophoretic spots were subjected to protein identification by mass spectrometry, only 9 of which were identified. Differential spots are shown in Figure S1A. Principal component analysis performed to evaluate variations in the datasets showed that control samples were well distinct from $\mathrm{Rai}^{-1-}$ samples (Figure S2A). Among the differential spots that were up-regulated in $\mathrm{Rai}^{-/-}$astrocytes we found proteasome subunit beta type 2 (PSB2), ubiquitin-conjugating enzyme E2 N (UBE2N), superoxide dismutase (SODC), and terminal nucleotidyl transferase 5C (TET5C), while among the down-regulated spots we found alpha enolase (ENOA), heat shock cognate $71 \mathrm{kDa}$ protein (HSP7C), NADH dehydrogenase iron-sulfur protein 2 mitochondrial (NDUS2), tubulin beta-2A chain (TBB2A), and astrocytic phosphoprotein PEA-15 (PEA15) (Figure 2A box plot, Table S1A). Hierarchical clustering analysis of proteins significantly altered in abundance demonstrated consistent replicate samples within one group and difference between control and $\mathrm{Rai}^{-1-}$ astrocytes (Figure 2A heat map). 


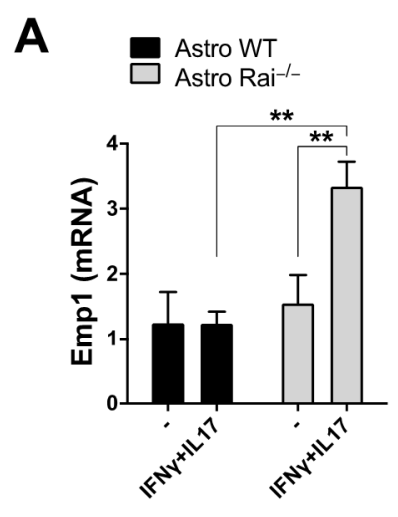

C

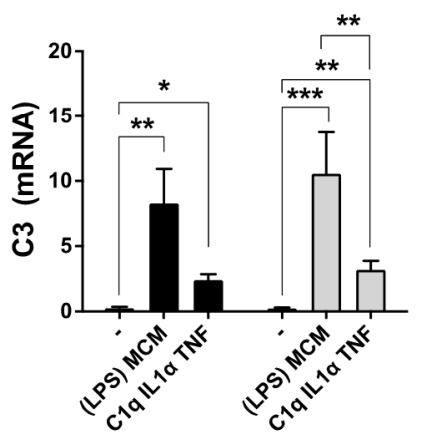

Astro WT

Astro Rai ${ }^{-1}$

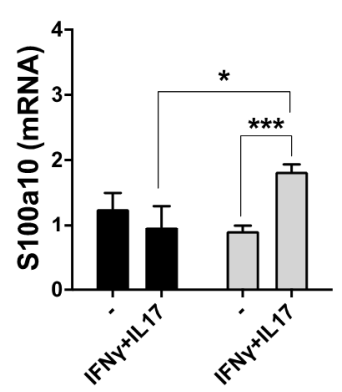

B
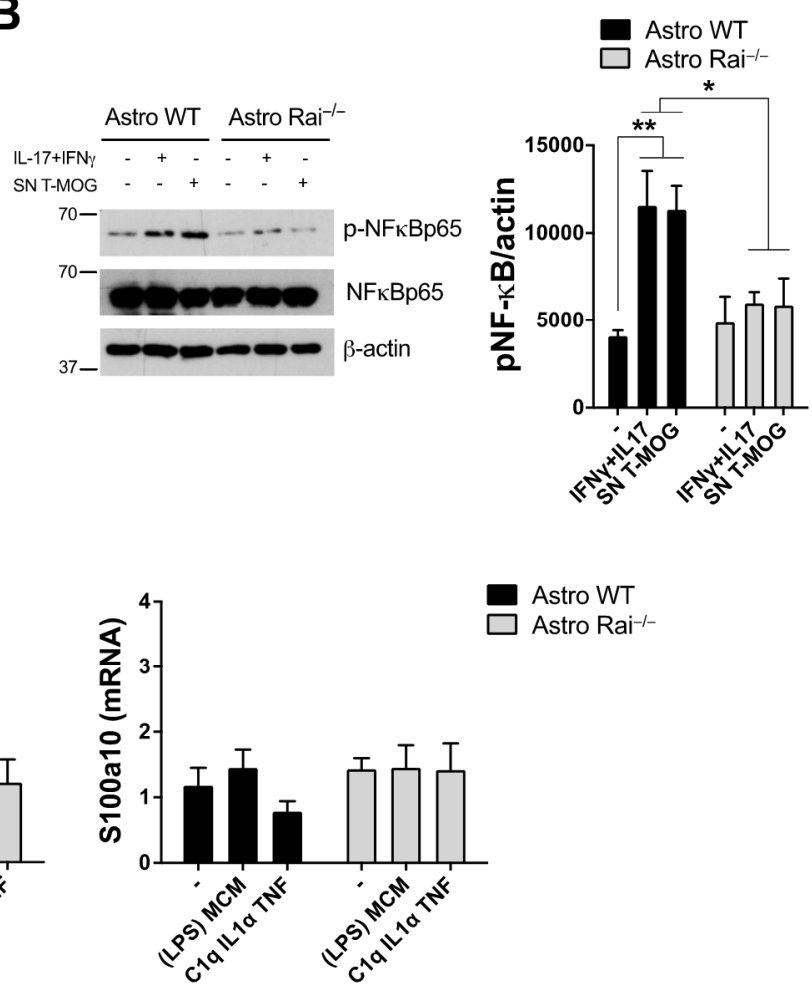

Astro WT Astro Rai ${ }^{-/-}$

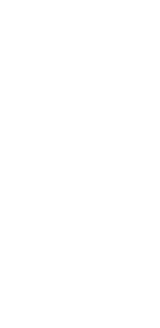

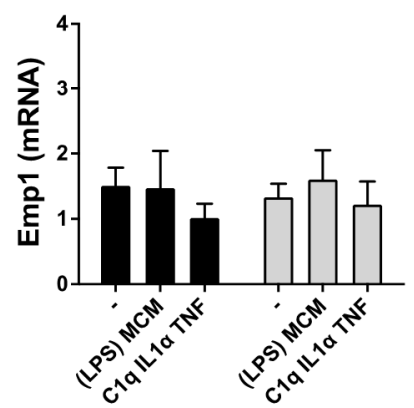

Figure 1. Rai signaling controls astrocyte reaction to soluble factors secreted by MOG-specific T cells, but not by microglia. (A) qRT-PCR analysis of Emp1 and S100a10 transcripts in WT (Astro WT) and Rai ${ }^{-/-}$(Astro Rai ${ }^{-/-}$) astrocytes untreated (-) or treated for $24 \mathrm{~h}$ with a combination of IFN $\gamma(10 \mathrm{ng} / \mathrm{mL})$ and IL-17 (50 ng/mL) (IFN $\gamma+$ IL-17). Data are presented as mean value $\pm \mathrm{SD}(n=4)$; (B) Immunoblot analysis of phosphorylated NF- $k B$ in lysates of WT (Astro WT) and Rai ${ }^{-/-}$ (Astro Rai ${ }^{-/-}$), astrocytes untreated or treated for $15 \mathrm{~min}$ at $37^{\circ} \mathrm{C}$ with culture supernatants from MOG-specific T cells or as in (A). Actin and NF-kB were used as loading control. The histogram shows the quantification by densitometric analysis of the levels of phosphorylated NF- $\mathrm{kB}$ relative to actin $(n=4)$; (C) qRT-PCR analysis of C3, Emp1, and S100a10 transcripts in WT (Astro WT) and Rai ${ }^{-/-}$(Astro Rai ${ }^{-/-}$), astrocytes untreated or treated for $24 \mathrm{~h}$ at $37^{\circ} \mathrm{C}$ with culture supernatants from LPS-activated microglia (LPS-MCM) or with a combination of IL-1 $\alpha(3 \mathrm{ng} / \mathrm{mL}), \mathrm{TNF}(30 \mathrm{ng} / \mathrm{mL})$, and C1q $(400 \mathrm{ng} / \mathrm{mL})$. Data are presented as mean value $\pm \mathrm{SD}\left(n=5\right.$ for LPS-MCM, $n=3$ for IL- $1 \alpha, \mathrm{TNF}$, and C1q). ${ }^{* * *} p<0.001,{ }^{* *} p<0.01$, ${ }^{*} p<0.05$.

In order to investigate the global changes in protein composition induced by IL-17 and the impact of Rai expression on these changes, we next compared the proteome of IL-17-treated control and $\mathrm{Rai}^{-/-}$astrocytes. A mean of 2252 spots was detected in each gel (Figure S1B). Through image and statistical analyses, we identified glial fibrillary acidic protein (GFAP) among the proteins that were up-regulated in $\mathrm{Rai}^{-/-}$astrocytes treated with IL-17 compared to their wild-type counterparts (Figure 2B, Table S1A).

Enrichment analysis performed using the MetaCore 6.8 network building tool (Clarivate Analytics, Philadelphia, PA, USA) shed light on the molecular pathways associated to the identified differential proteins (Figure 2). In particular, differential proteins found under basal conditions were involved in some potentially relevant pathways such as the putative ubiquitin pathway, the HSP70-dependent folding pathway, the HSP70/TLR signaling pathway, the negative regulation of HIF- $1 \alpha$ function, and TGF-beta-induction of EMT via ROS (Figure 2A, Table S2). GFAP, which is involved in astrocyte differentiation pathway, was the only differentially identified protein in IL-17-treated samples. 
A

\section{Astrocytes - UNTREATED}
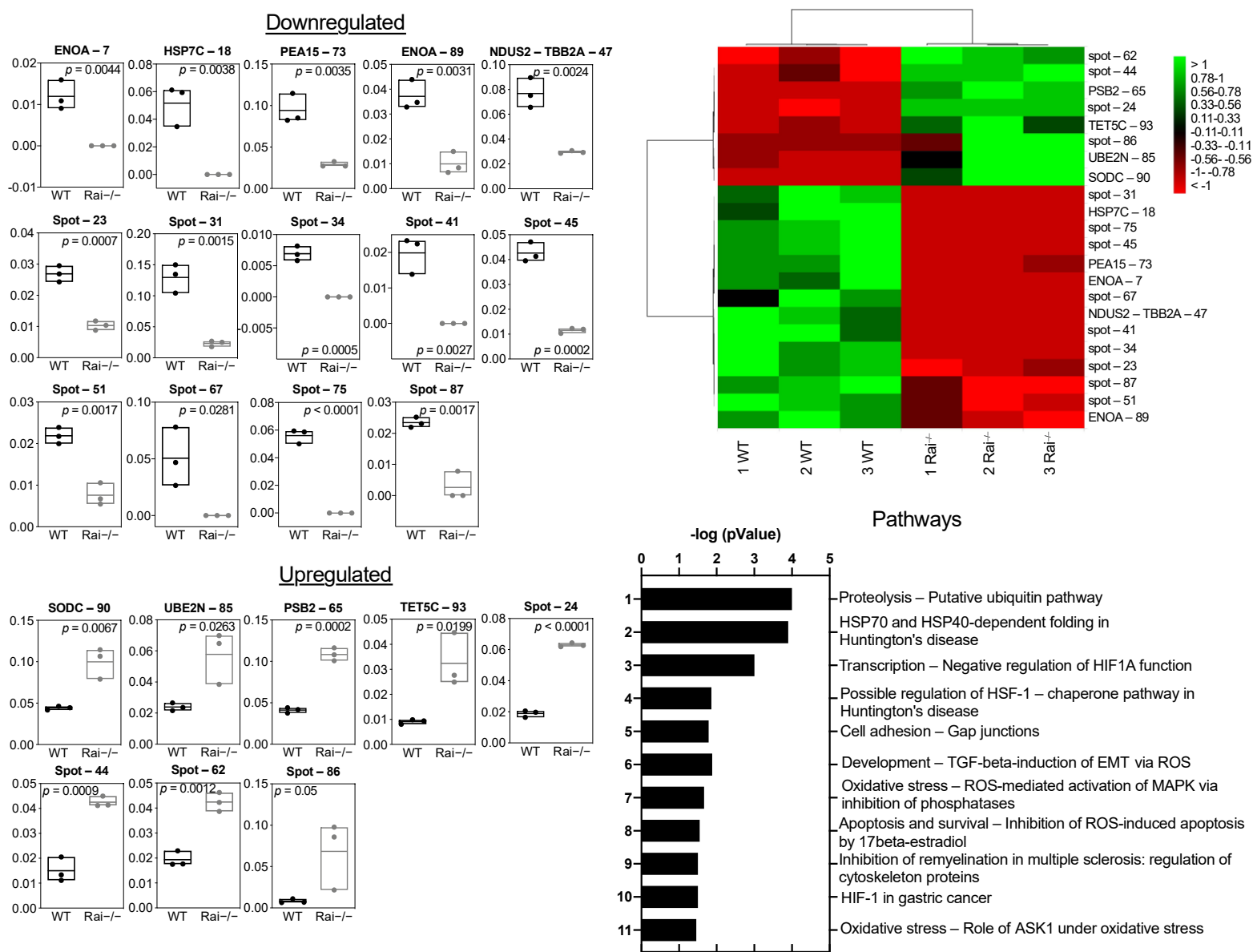

B

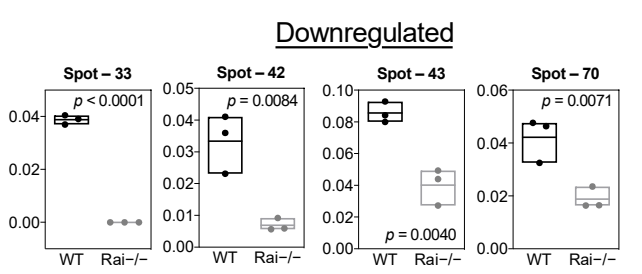

Pathways

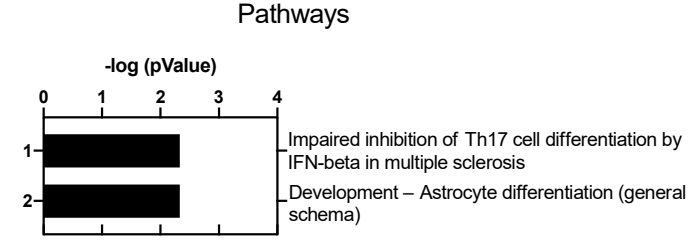

Astrocytes - IL-17

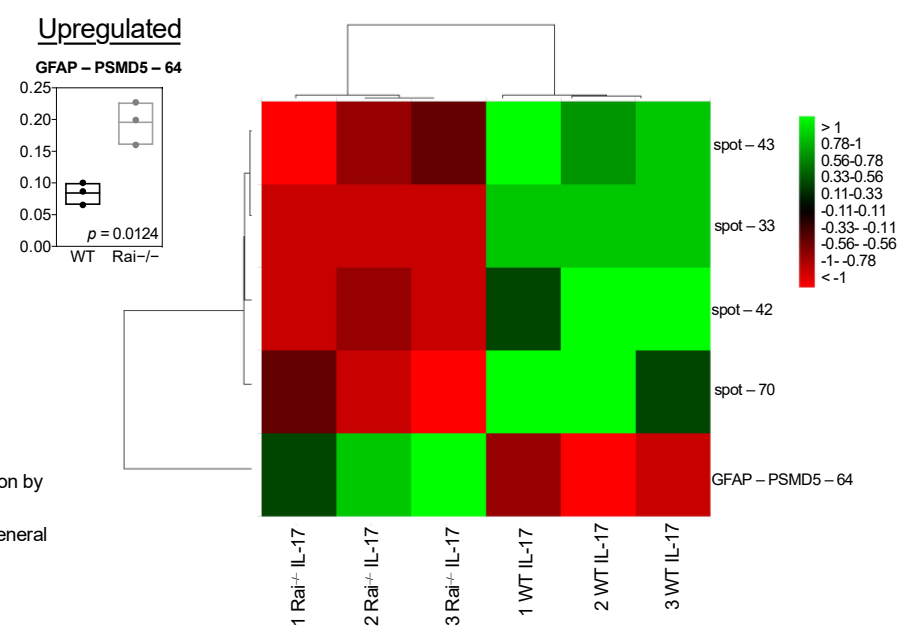

Figure 2. Differential proteomic analysis of control and Rai ${ }^{-/-}$astrocytes. Supervised hierarchical clustering heat map (left) and floating bars (min to max) (right) of differentially abundant proteins found in untreated (A) and IL-17-treated (B) astrocytes purified from control (WT) and $\mathrm{Rai}^{-/-}$mice $\left(n=3 \mathrm{WT}, 3 \mathrm{Rai}^{-/-}\right)$. Heat maps: columns correspond to individual preparations of astrocytes and row to spot identity (protein name, or spot number for not identified spots) is indicated on the right. Color scale (from high value in green to low value in red) illustrates \% volume values of the statistically significant differentially abundant spots. The most relevant pathway maps reported by MetaCore, based on all differentially expressed proteins and prioritized according to their statistical significance $(p \leq 0.001)$, are shown for each condition. 


\subsection{Differential Proteome Profile of Control and Rai ${ }^{-1-}$ Astrocytes-Derived Extracellular Vesicles}

Our finding that astrocytic Rai is required for the generation of a pro-inflammatory CNS microenvironment $[16,17]$, together with the key role played by ADEVs in shaping the surrounding microenvironment [2], prompted us to explore the impact of Rai on the ADEV proteome both under basal condition and in response to IL-17.

ADEVs from both untreated and IL-17-treated control and $\mathrm{Rai}^{-/-}$astrocytes were isolated using a sequential ultracentrifugation and the protein content was characterized by 2DE and image analysis. Under basal conditions, we found a mean of 694 spots per gel. The quantitative comparison of the normalized \% volume values for each spot revealed 14 differentially abundant spots validated by statistics in Rai ${ }^{-/}$ADEVs compared with WT ADEVs. Differential spots are shown in Figure S3A, eight of which were identified by mass spectrometry (Figure 3A box plot, Table S1B). Principal component analysis revealed that WT and $\mathrm{Rai}^{-1-}$ ADEVs were well separated (Figure S2A). Identified proteins that were down-regulated in $\mathrm{Rai}^{-/-}$ADEVs compared with WT ADEVs were Rab3 GTPase-activating protein non-catalytic subunit (RBGPR), protein disulfideisomerase A3 (PDIA3), thiosulfate sulfurtransferase/rhodanese-like domain-containing protein 2 (TSTD2), alpha-enolase (ENOA), glutamine synthetase (GLNA), kelch-like protein 9 (KLHL9), and microtubule-associated protein 4 (MAP4), while S10A6 was present only in WT ADEVs (Figure 3A box plot, Table S1B).

A mean of 660 spots per gel was found in control and Rai ${ }^{-/-}$ADEVs following IL-17 treatment. Seven differentially abundant spots were extrapolated and are shown in supplementary Figure 3B. Six were identified (Figure 3B, Table S1B). These include actin cytoplasmic 1 (ACTB), peroxiredoxin-6 (PRDX6), heat shock factor-binding protein 1 (HSBP1), actin aortic smooth muscle (ACTA), and MAP4, which were enriched in IL-17$\mathrm{Rai}^{-1-}$ ADEVs compared with IL-17-WT ADEVs. Moreover, the endoplasmic reticulum resident protein 44 (ERP44) was detected only in IL-17-Rai ${ }^{-/-}$ADEVs (Figure 3B box plot). MAP4 is the only protein shared in these conditions (basal versus IL-17). Interestingly, it was found to be enriched in IL-17 $\mathrm{Rai}^{-/-}$ADEVs compared with IL-17-WT ADEVs and conversely, under basal conditions, it was less abundant in Rai ${ }^{-/}$ADEVs compared with WT ADEVs (Figure 3 box plot). Principal component analysis and hierarchical clustering of significant differential spots showed that WT ADEVs and Rai ${ }^{-/}$ADEVs cluster furthest away from each other (Figure 3B heat map, Figure S2B). Moreover, in basal conditions, we observed a predominance in low-abundance proteins in $\mathrm{Rai}^{-/-}$ADEVs with respect to WT ADEVs, while in IL-17 stimulated condition, we observed an opposite behavior, indicating that Rai impinges on the ADEV proteome in both conditions (Figure 3).

Pathway analyses of the identified proteins under basal conditions highlighted their involvement in several pathways, including beta-catenin dependent transcription regulation, nitrogen metabolism, Wnt signaling of oligodendrocyte differentiation, GABAergic neurotransmission, HIF-1-dependent transcription, glycolysis and gluconeogenesis, and histidine-glutamate-glutamine metabolism, and plasmin signaling.

On the other hand, pathway analysis of the IL-17-treated condition showed their involvement in the regulation of the HSF-1/chaperone pathway, dysregulation of adiponectin secretion, regulation of cytoskeleton proteins in oligodendrocytes differentiation, plasmalogen biosynthesis, and oxidative stress (Figure 3, Table S3).

Since the ADEV proteome might reflect the cellular changes induced by Rai, we performed a protein network using all the proteomic data obtained in wild type astrocytes and ADEVs and those obtained in $\mathrm{Rai}^{-/-}$astrocytes and Rai ${ }^{-/-}$ADEVs to identify the most relevant molecular pathways influenced by Rai. The protein network, presented in Figure 4A, showed the proteasome (20S core), HSP70, ENO1, and SOD1 as central functional hubs. These proteins are relevant players in the proteasome ubiquitin system, unfolding protein response, ECM remodeling/cell adhesions, and oxidative stress response, respectively. 


\section{A}

ADEVs - UNTREATED
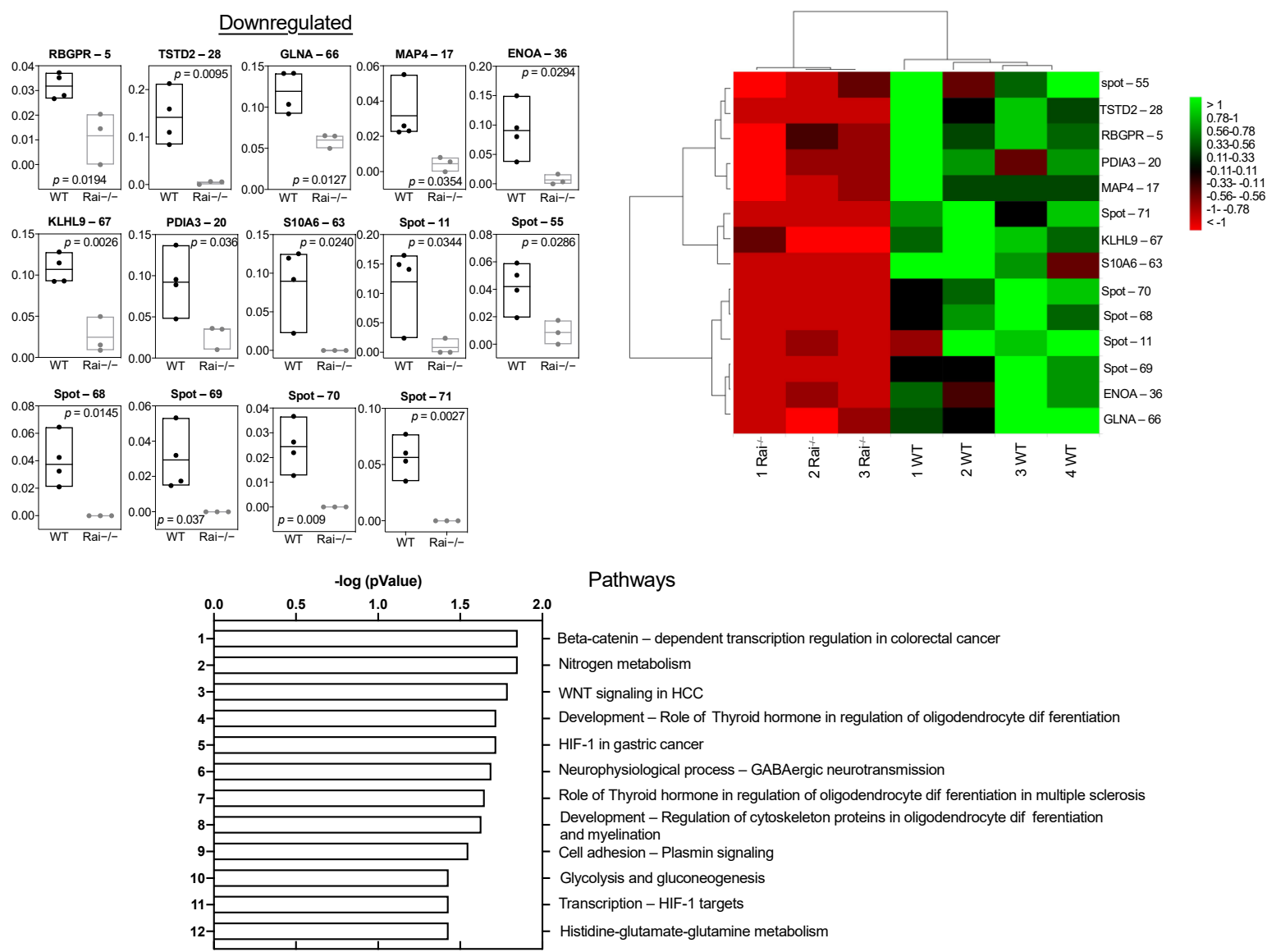

Pathways

Beta-catenin - dependent transcription regulation in colorectal cance Nitrogen metabolism

WNT signaling in $\mathrm{HCC}$

Development - Role of Thyroid hormone in regulation of oligodendrocyte dif ferentiation HIF-1 in gastric cancer

Neurophysiological process - GABAergic neurotransmission

Role of Thyroid hormone in regulation of oligodendrocyte dif ferentiation in multiple sclerosis Development - Regulation of cytoskeleton proteins in oligodendrocyte dif ferentiation and myelination

Cell adhesion - Plasmin signaling

Glycolysis and gluconeogenesis

Transcription - HIF-1 targets

Histidine-glutamate-glutamine metabolism

B
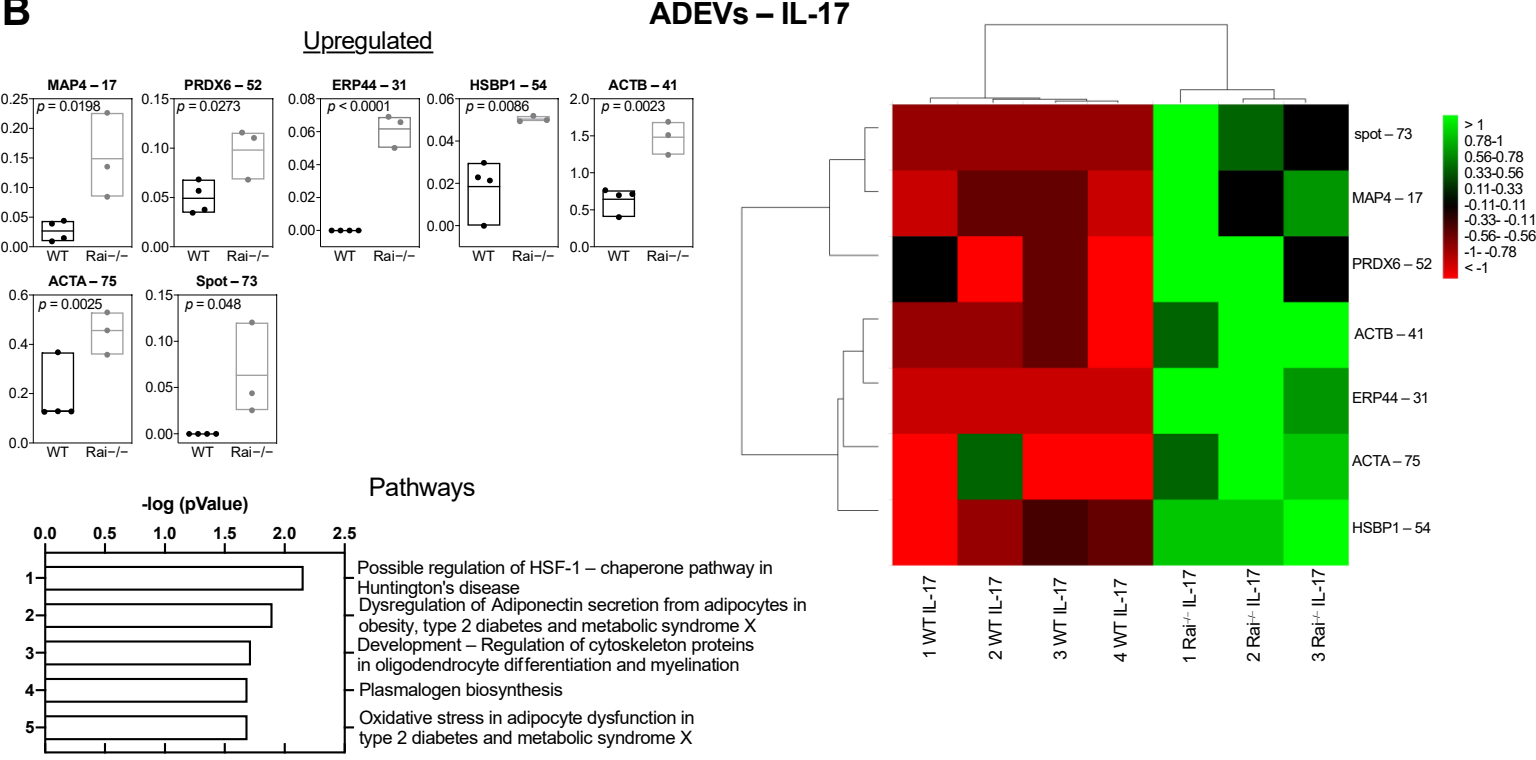

Figure 3. Differential proteomic analysis of control and Rai-/- ADEVs. Supervised hierarchical clustering heat map (left) and floating bars (min to max) (right) of differentially abundant proteins found in ADEVs purified from the cell media of control (WT) and $\mathrm{Rai}^{-/-}$astrocytes untreated (A) and treated with IL-17 (B) ( $\left.n=4 \mathrm{WT}, 3 \mathrm{Rai}^{-/-}\right)$. Heat maps: columns correspond to individual preparations of ADEVs and row to spot identity (protein name, or spot number for not identified spots). Color scale (from high value in green to low value in red) illustrates \% volume values of the statistically significant differentially abundant spots. The most relevant pathway maps reported by MetaCore, based on all differentially expressed proteins and prioritized according to their statistical significance $(p \leq 0.001)$, are shown for each condition. 


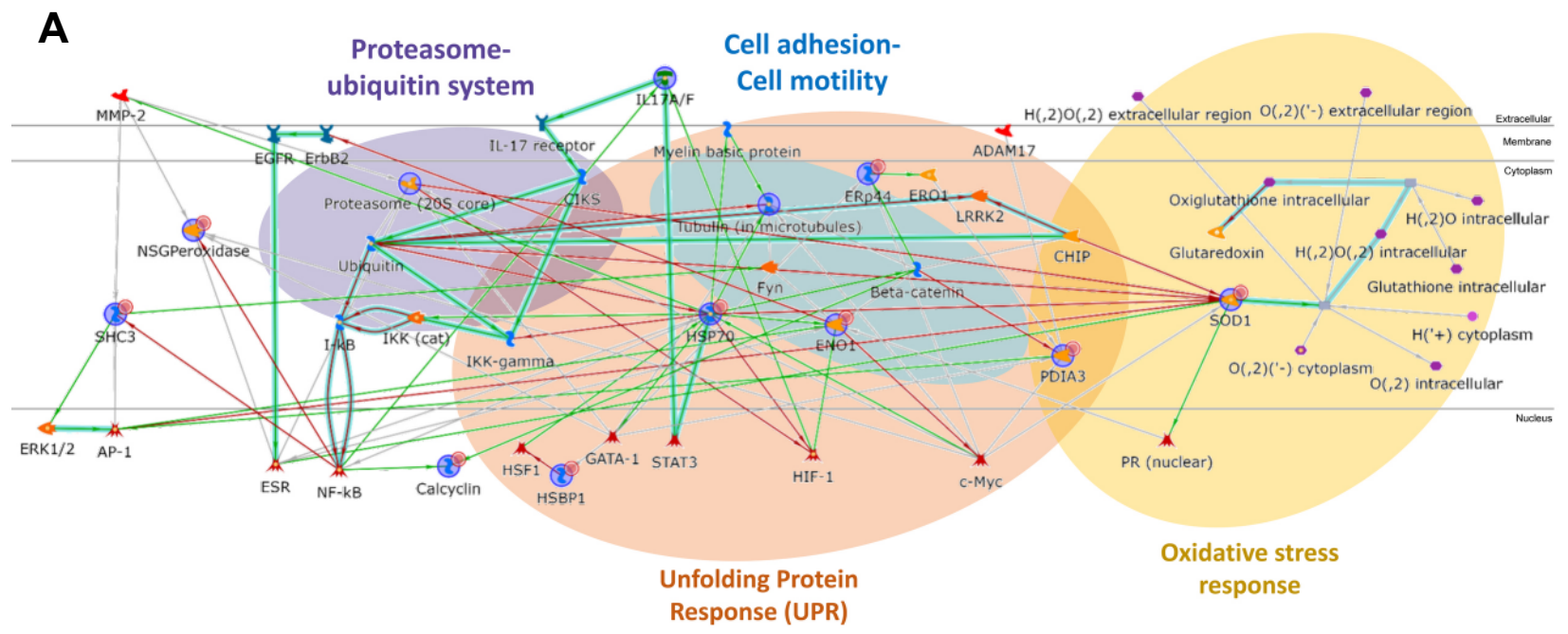

B

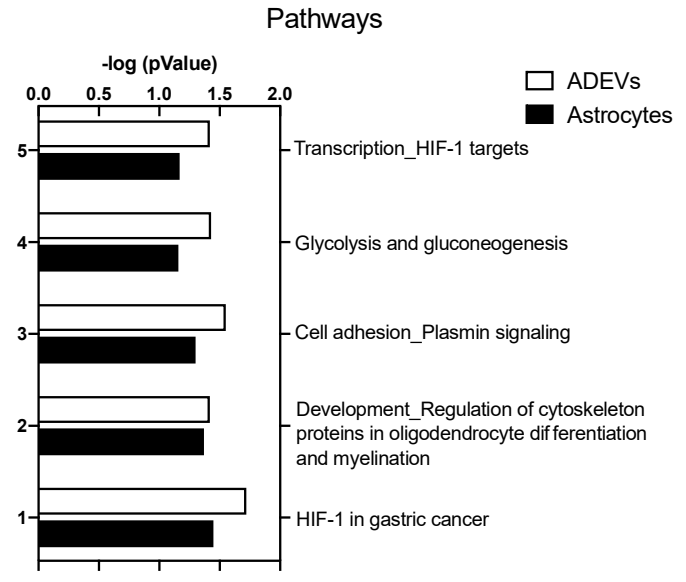

C

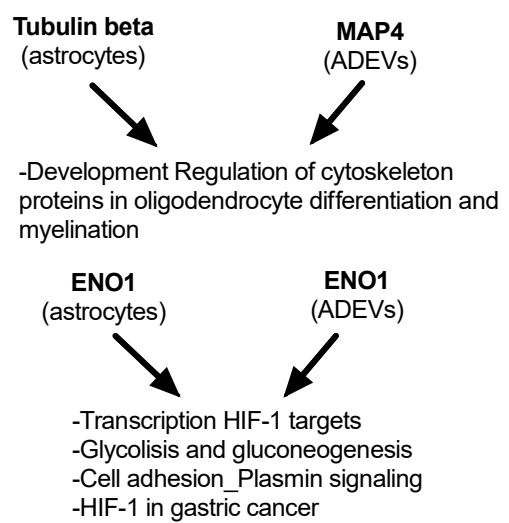

Figure 4. Protein network and pathways influenced by Rai in astrocytes and ADEVs. (A) Protein network analysis by using all the proteomic data obtained in WT astrocytes and ADEVs and those obtained in Rai ${ }^{-/-}$astrocytes and Rai ${ }^{-/-}$ADEVs. Proteasome (20 S core), HSP70, ENOA, and SOD1 are central functional hubs; (B) Pathway analysis comparison of the differential proteins found in astrocytes and ADEVs; (C) Association of differential proteins to the molecular pathways resulting from pathway analysis comparison of astrocytes and ADEVs.

In addition, a pathway analysis comparison of differential proteins between astrocytes and ADEVs was performed. HIF- $1 \alpha$ pathway and cellular energetic metabolism were among the most statistically significant shared relevant molecular pathways, together with the involvement of regulation of cytoskeleton proteins in oligodendrocyte differentiation and myelination (Figure 4B, Table S4). In particular, ENO1 dysregulation was related to HIF-1 pathway, glycolysis and gluconeogenesis, and plasmin signaling, while tubulin beta and MAP4 influenced the regulation of cytoskeleton proteins in oligodendrocytes differentiation and myelination (Figure 4C, Table S4).

\subsection{ENOA and HSP70 Provide New Insights into the Response of Rai ${ }^{-/-}$Astrocytes to IL-17}

The characterization of the proteomes of both astrocytes and ADEVs suggests that the differentially abundant proteins cooperate in specific molecular pathways, such as the HIF- $1 \alpha$ transcriptional pathway, the unfolding protein response, cellular energetic metabolism, the proteasome-ubiquitin system, cell adhesion-cell motility, and oxidative 
stress. Among the differentially expressed proteins, two of these, namely ENOA and HSP7C, a member of the HSP70 family, attracted our attention because of the involvement of ENOA in the regulation of ECM degradation, ROS and NO production [20], and the ability of HSP70 to modulate cytokine-dependent NF- $\mathrm{KB}$ activation and NO production in astrocytes [21,22]. Control and $\mathrm{Rai}^{-/-}$astrocytes were treated for $24 \mathrm{~h}$ with IL-17 or left untreated, and HSP70 and ENOA protein levels were analyzed by immunoblot. ENOA was found to be significantly reduced in astrocytes lacking Rai under basal conditions compared with control astrocytes (Figure 5A). In contrast, Rai deficiency resulted in a significant upregulation of HSP70 following IL-17 treatment compared with control astrocytes (Figure 5A). Of note, reduced NF-kB activation was observed in astrocytes lacking Rai compared with control astrocytes following IL-17 treatment (Figure 5B).

A
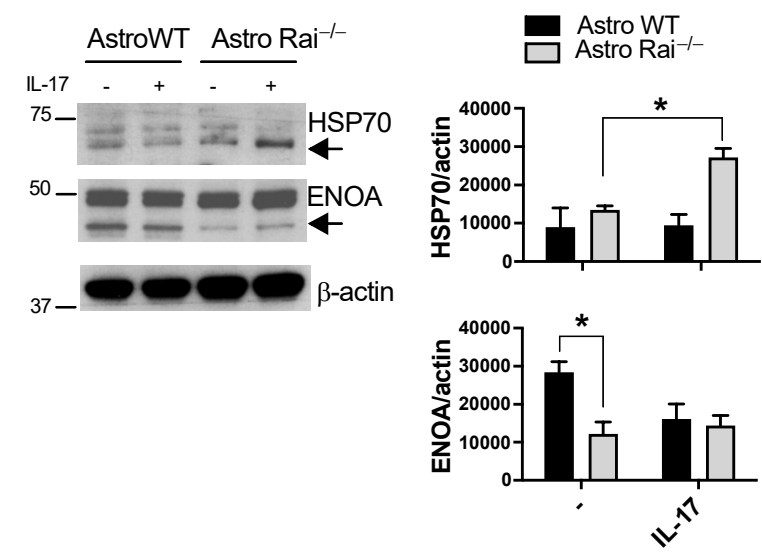

C

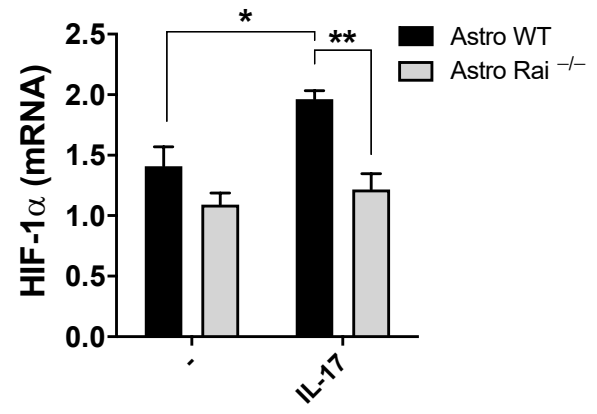

B

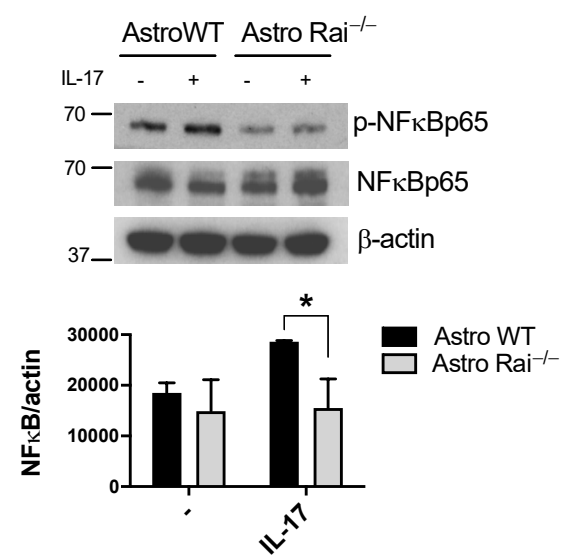

D

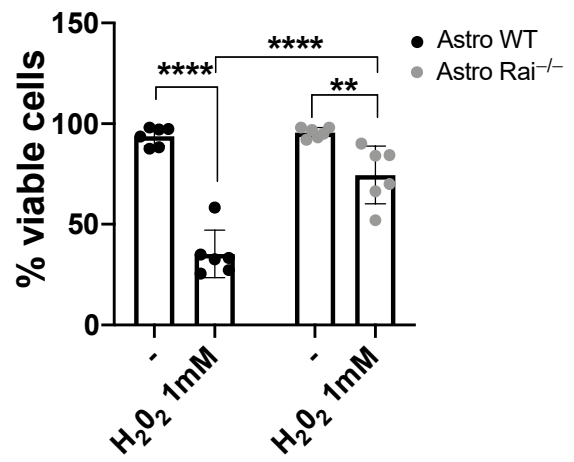

Figure 5. Rai supports the IL-17-dependent neuroinflammatory response in astrocytes through the activation of NFKB-HIF$1 \alpha$ pathway and the inhibition of HSP70 upregulation. (A) Immunoblot analysis of HSP70 and ENOA in lysates of WT (Astro WT) and $\mathrm{Rai}^{-/-}$(Astro Rai ${ }^{-/-}$) astrocytes untreated or treated with IL-17 (50 ng/mL) for 24 h; (B) Immunoblot analysis of phosphorylated and total NF- $\mathrm{kB}$ in lysates of WT (Astro WT) and Rai ${ }^{-/-}$(Astro Rai ${ }^{-/-}$) astrocytes treated with IL-17 for $15 \mathrm{~min}$ at $37^{\circ} \mathrm{C}$ or left untreated. Histograms showed in (A) and (B) represent the quantification by densitometric analysis of the levels of the indicated proteins relative to actin $(n=3)$; (C) qRT-PCR analysis of HIF- $1 \alpha$ transcripts in WT (Astro WT) and $\mathrm{Rai}^{-/-}$(Astro Rai ${ }^{-/-}$,) astrocytes treated as in (A). Data are presented as mean value \pm SD $(n=3) ;(\mathbf{D})$ Flow cytometric analysis of WT (Astro WT) and $\mathrm{Rai}^{-/-}$(Astro Rai ${ }^{-/-}$,) astrocytes treated with $1 \mathrm{mM} \mathrm{H}_{2} \mathrm{O}_{2}$ for $24 \mathrm{~h}$ at $37^{\circ} \mathrm{C}$ and stained with PI immediately before the acquisition. The graph shows the mean value $\pm \mathrm{SD}$ of the percentage of PI negative cells (viable cells) $(n=6) .{ }^{* * *} p<0.0001,{ }^{* *} p<0.01,{ }^{*} p<0.05$.

Pathway analysis comparison highlighted HIF1- $\alpha$ as a crucial transcription factor linked to both HSP70 and ENOA (Figure 4). HIF1- $\alpha$, whose expression is controlled by NF$\mathrm{\kappa B}[23]$, promotes the expression of iNOS and ENOA in response to cytokine stimulation 
and hypoxia, respectively $[24,25]$. We therefore compared HIF- $1 \alpha$ mRNA levels in Rai ${ }^{-/-}$ and control astrocytes. As opposed to WT astrocytes, $\mathrm{Rai}^{-/-}$astrocytes did not upregulate HIF- $1 \alpha$ mRNA levels following IL-17 treatment, consistent with the reduced activation of NF- $\mathrm{kB}$ (Figure 5C).

High levels of ROS, resulting at least in part from the dysregulated antioxidant function of astrocytes, are found in both EAE and MS lesions and are responsible for neurodegeneration [26,27]. Our proteomic results revealed that many of the proteins differentially expressed between control and $\mathrm{Rai}^{-1-}$ astrocytes are involved in the cellular oxidative stress response (Figure 4). To address whether Rai participates in the response of astrocytes to oxidative stress, control and $\mathrm{Rai}^{-/-}$astrocytes were added with $\mathrm{H}_{2} \mathrm{O}_{2}$ and cultured for $24 \mathrm{~h}$, followed by PI cell viability assay. $\mathrm{H}_{2} \mathrm{O}_{2}$ treatment caused a significant reduction in cell viability of control astrocytes at $1000 \mathrm{mM}$ when compared with untreated samples. Rai deficiency prevented the decrease in cell viability of astrocytes upon $\mathrm{H}_{2} \mathrm{O}_{2}$ induced oxidative stress when compared with controls (Figure 5D), indicating that Rai deletion protects astrocytes from extracellular ROS.

\section{Discussion}

MS is an autoimmune neurodegenerative disease of the CNS characterized by the presence of demyelinated lesions in the brain and spinal cord and local inflammatory reaction [28]. How inflammation is connected to demyelination in MS is still an open question and several mechanisms have been proposed [29]. The low number of lymphocytes found at the site of active demyelination [29], as well as the finding that active demyelination can occur far from the immune cell infiltrates [30], led to speculation that soluble factors released by immune cells drive tissue injury through the direct or indirect activation of nearby cells, including microglia and astrocytes which are present in MS lesions [29,31]. Importantly, a direct link between immune cell-induced astrocyte response and neuronal and oligodendroglial cell death has been demonstrated in MS [18]; however, we still lack a full understanding of how astrocyte dysregulation drives disease. Although the acquisition of a neurotoxic state by astrocytes has been documented in response to soluble factors released by LPS-activated microglia [6], little is known about the nature of signals coming from infiltrating $\mathrm{T}$ cells during MS and their influence on astrocyte function. We recently identified Rai as a key signaling molecule in the control of the astrocyte reaction to conditioned media from encephalitogenic T cells [17] and here we further corroborate a role for Rai in the astrocyte response to the Th17 cell-secreted cytokines IL-17 and IFN $\gamma$, but not to pro-inflammatory mediators secreted by activated microglia. Importantly, here, we found an association between Rai and the activation of the transcription factor NF- $\kappa B$ in the control of the astrocyte reaction to soluble factors released by encephalitogenic $T$ cells.

Proteomic analysis performed on astrocytes indicated a specific contribution of Rai in neurotoxic pathways such as the unfolded protein response, which has been previously identified, together with the activation of NF- $\mathrm{KB}$, as one of the main pathways implicated in the pathogenic activities of astrocyte in EAE and MS [13]. Moreover, our analysis identified the proteasome-ubiquitin system, which is the main pathway for protein degradation in mammals, as a pathway influenced by Rai (Figure 4). Heat shock proteins are molecular chaperones responsible for the proper folding of proteins under physiological condition and in preventing protein aggregation and cell death following cellular stress, including hypoxia, oxidative stress, and exposure to inflammatory cytokines [32]. Among HSPs, HSP70 over-expression in astrocytes has been shown to promote neuroprotection by directly interacting with and inhibiting NF- $\mathrm{kB}$, which in turn suppresses inducible NO synthase and pro-inflammatory cytokine expression [21]. Interestingly, upregulation of HSP70 in MS lesions has been suggested as a mechanism to counteract the inflammatory and oxidative microenvironment that is characteristic of the disease [32-34]. Our finding that HSP70 is upregulated in $\mathrm{Rai}^{-/-}$astrocytes following IL-17 treatment paralleled by NF- $\mathrm{kB}$ inhibition highlights a role for Rai in the modulation of the IL-17-dependent unfolded protein response and proteasome-ubiquitin system in astrocytes. Moreover, the enhanced 
ability of $\mathrm{Rai}^{-/-}$astrocytes to survive oxidative stress compared with control astrocytes further highlights the contribution of astrocytic Rai to neurodegeneration, at least in part by restraining the upregulation of HSP70.

Hypoxia-inducible factors- $1 \alpha$ (HIF- $1 \alpha)$ is a master transcription factor controlling cellular responses to hypoxia [35,36]. Beside hypoxia, HIF-1 $\alpha$ upregulation can be induced by ROS, RNS, and pro-inflammatory cytokines, the latter through the activation of NF$\kappa B[23,35]$. In astrocytes, IL-17-dependent upregulation of HIF- $1 \alpha$ has been demonstrated to contribute to the production of the pro-inflammatory cytokines IL-1 $\beta$ and IL-6 [36]. Moreover, HIF- $1 \alpha$-dependent upregulation of iNOS expression following TNF, IL-1, and IFN $\gamma$ treatment has been recently shown in primary human astrocytes under normoxic condition [24]. We have previously shown that Rai deficiency in astrocytes impairs the production of IL-6 and iNOS following IL-17 and IFN $\gamma$ treatment, respectively [16]. Here we show that the IL-17-dependent expression of HIF- $1 \alpha$ is inhibited in $\mathrm{Rai}^{-/-}$astrocytes. These data, together with the finding that Rai modulates NF-KB activation and HIF- $1 \alpha$ expression in T cells under hypoxia [37], suggest that the mechanism by which IL-17 promotes the pro-inflammatory function of astrocytes depends at least in part on the activation of the Rai/NF- $\mathrm{kB} / \mathrm{HIF}-1 \alpha$ axis. Of note, during neuroinflammation hypoxia has been shown to increase oxidative stress and to contribute to brain barrier dysfunction [38]. In addition, our pathway analysis results indicate that ENOA is correlated to HIF- $1 \alpha$ activity. This multifunctional glycolytic enzyme migrates from the cytoplasm to the cell surface of macrophages, microglia, and astrocytes under inflammatory conditions to promote ECM degradation and the production of pro-inflammatory mediators including cytokines (IL-6, IL-1 $\beta$, TNF- $\beta$, and TNF- $\alpha$ ), chemokines (MCP-1 and MIP- $1 \alpha$ ), reactive oxygen species (ROS), and nitric oxide (NO) [20]. Accordingly, we found that ENOA expression is impaired in $\mathrm{Rai}^{-/-}$astrocytes (Figure 5A), further supporting the notion that Rai-driven HIF- $1 \alpha$ activation may be responsible for astrocyte reprogramming towards a neurotoxic phenotype.

CNS inflammation during MS is characterized by the accumulation of highly reactive molecules into the extracellular space, such as ROS, RNS, and toxic glutamate, as a consequence of both increased production by activated leukocytes, macrophage, and microglia, and impaired detoxification which is mainly operated by astrocytes [39]. Astrocytes are indeed strongly equipped with antioxidant machineries through which they counteract the failure of cerebral homeostasis in the injured CNS. Additionally, they are actively implicated in the control of the extracellular levels of glutamate, the main excitatory neurotransmitter, which under physiological conditions, is rapidly removed from the microenvironment via specific transporters and converted into glutamine by astrocytes [1] In MS patients, enhanced concentration of extracellular glutamate, oxidative stress, iron accumulation, mitochondrial injury, and ion channel dysfunction have been documented and indicated among others as causes of neurodegeneration [28]. Together with our previous report showing reduced astrogliosis and demyelination in the EAE $\mathrm{Rai}^{-/-}$mice [16], these findings identify Rai as a driver of IL-17 dependent, disease-promoting astrocyte pathogenic activities.

EVs have been recognized as key mediators of cell-cell communication between neurons, astrocytes, microglia, and oligodendrocytes both under physiological and pathological conditions, and accumulating evidence indicates that ADEVs can regulate neuronal survival and maturation [40]. Interestingly, ADEVs containing apolipoprotein D have been recently shown to be internalized by neurons and to protect them against oxidative stress [41]. Additionally, oxidative stress-induced ADEVs promote the survival of neurons by transferring Synapsin I [42]. At present, only few reports have investigated how specific stimuli impact on the protein composition of ADEVs. Datta Chaudhuri et al. [43] identified a stimulus-dependent protein composition of ADEVs implicated in the support of neurite outgrowth and neuronal survival following ATP or IL-10 stimulation and, conversely, an enrichment in proteins supporting immune cell infiltration following treatment with the pro-inflammatory cytokine IL- $1 \beta$. Although it has been demonstrated that EVs con- 
tribute to neuroinflammation and neurotoxicity in MS [44], to our knowledge, no data are available on the protein composition of ADEVs shed in response to T cell soluble factors [40]. Astrocyte reaction contributes to the remyelination process in MS through the secretion of soluble factors that both support and inhibit oligodendrocyte progenitor cell proliferation, differentiation, and migration [31]. We can hypothesize that Rai, by modulating the protein contents of ADEVs, might modulate neuron and oligodendrocyte function during MS. Indeed, $\mathrm{Rai}^{-/-} \mathrm{ADEV}$ s contain seven proteins which were enriched when compared with WT ADEVs, of which one is a protein unique to $\mathrm{Rai}^{-/-}$ADEVs, Erp44. Erp44 is a chaperone protein that promotes normal protein folding and among other things is involved in adiponectin folding [45]. Adiponectin, an adipose tissue-derived cytokine, has been found to limit CNS autoimmune inflammation in EAE mice by restraining Th17 differentiation [46] and to limit the LPS-induced pro-inflammatory phenotype of microglia [47]. IL-17-dependent secretion of Erp44 in Rai ${ }^{-/-}$ADEVs therefore appears as an additional mechanism by which astrocytes lacking Rai limit neuroinflammation by counteracting the pathogenic function of both Th17 cells and microglia. Similar to Erp44, increased levels of microtubule-associated protein 4 (MAP4) and PRDX6 were found in $\mathrm{Rai}^{-1-}$ ADEVs compared with control ADEVs in response to IL-17 treatment of astrocytes. MAP4, together with other MAPs, is involved in the regulation of the microtubule network during the differentiation of myelin-forming oligodendrocytes [48]. PRDX6 protects the myelin sheet against oxidative stress [49]. Hence, the higher levels of MAP4 and PRDX6 found in $\mathrm{Rai}^{-/-}$ADEVs further support the notion that astrocytes lacking Rai are able to prevent demyelination during EAE also through the secretion of EVs. These data show for the first time that EVs released by $\mathrm{Rai}^{-/-}$astrocytes in response to an inflammatory stimulus, IL-17, may provide protection against oxidative cellular stress to bystander cells, thereby contributing to prevent demyelination.

Collectively, data obtained in this and our previous studies in primary mouse astrocytes established Rai as a novel participant in the as yet largely unknown signaling pathways driving the astrocyte reaction in response to pro-inflammatory signals, whether Rai subserves other functions in astrocytes is unknown. At present, there are no models with targeted deletion of Rai in astrocytes which will allow to validate Rai as a critical regulator of astrocytes function in vivo.

With the caveat that the role of astrocytic Rai in the healthy brain is unknown, we know that Rai expression in neuron is developmentally regulated and reaches its peak in postmitotic neurons where it promotes survival [50]. Nevertheless, upregulation of Rai expression in neuroblastomas and in brain tumors has been associated with disease progression and poor prognosis indicating that the beneficial role played by this protein in healthy neurons become deleterious under pathological conditions [50]. Molecular adaptors are protein lacking enzymatic activity, which play a key role in coupling surface receptor to intracellular signaling pathways and in the integration of signaling pathways originating from different receptors. As such, they finely regulate the cellular response to environmental clues. To perform their roles, adaptors form low affinity interactions with partner proteins in a flexible and transient manner, thereby ensuring a proper and dynamic control of the intracellular signaling cascades which ultimately lead to the activation of transcription factors. A molecular adaptor may not only amplify a stimulus but also attenuate it depending on the context, the adaptor concentration, and the post-translational modifications, which can dynamically change its function.

In this context, we can speculate that modulation of Rai expression and/or posttranslational modifications in astrocytes under different conditions may account, at least in part, for the ability of these cells to control multiple processes in health and disease. It is worth noting that different stress stimuli regulate Rai protein expression in brain tissues and in neuronal cells, suggesting an association between cellular response to a specific insult and modulation of Rai expression [51]. From an evolutionary point of view, the ability of cells to adapt to external stimuli orchestrating, via adaptor proteins, the strength and the duration of signaling cascades is an advantage. 
Relevant to MS and EAE, we can speculate that upregulation of Rai in astrocytes during disease course may be a driver of disease. Whether and how Rai expression is modulated in astrocytes under different stimulation/disease stage is an important issue to be addressed.

\section{Materials and Methods}

\subsection{Mice}

C57BL/6J Rai ${ }^{-/-}$mice generated as described [14,52] and C57BL/6J controls were used. Mice were housed in the animal facility at the University of Siena in pathogen-free and climate-controlled $\left(20 \pm 2{ }^{\circ} \mathrm{C}\right.$, relative humidity $\left.55 \pm 10 \%\right)$ conditions. The cages were provided with mouse houses and nesting material as environmental enrichment, and mice were provided with water and a pelleted diet ad libitum. Procedures and experimentation were carried out in accordance with the 2010/63/EU Directive and approved by the Italian Ministry of Health.

\subsection{Primary Astrocyte Culture and Treatments}

Astrocytes and microglia were purified from newborn (2-day-old) $\mathrm{Rai}^{-/-}$and C57BL/6J mice as described $[53,54]$ by using the Neural Tissue Dissociation kit (T) (Miltenyi Biotec, Bergisch Gladbach, Germany). Glial cells were cultured in flasks and maintained in Dulbecco's Modified Eagles Medium (DMEM) supplemented with 10\% BCS and $20 \mathrm{U} / \mathrm{mL}$ penicillin. After two weeks, the microglia-containing supernatant were collected and plated, while adherent astrocytes were trypsinized and replated. Purity of astrocytes and microglia was assessed by flow cytometry using anti-GFAP mAb (clone GA5, eBioscence) and anti-CD11b $\mathrm{mAb}$ (clone $\mathrm{M} 1 / 70, \mathrm{BD}-$ Biosciences) respectively $\left(\% \mathrm{GFAP}^{+}>95 \%, \% \mathrm{CD} 11 \mathrm{~b}^{+}>95 \%\right.$ ).

Treatments of astrocytes were performed in serum free medium with IL-17 $(50 \mathrm{ng} / \mathrm{mL})$, a combination of IL-17 (50 ng/mL) and IFN $\gamma(10 \mathrm{ng} / \mathrm{mL})$, or a mixture of IL-1a $(3 \mathrm{ng} / \mathrm{mL})$, TNF (30 ng/mL), and C1q (400 ng/mL). Alternatively, the culture medium was replaced with conditioned media from LPS-stimulated microglia or IL-2-stimulated MOG-T cells as described [6,17].

\subsection{RNA Purification, Reverse Transcription, and $q R T-P C R$}

RNA was purified from astrocytes by using the RNeasy Plus Mini Kit (Qiagen, Venlo, The Netherlands) according to the manufacturer's instructions, and RNA purity and concentration were measured using QIAxpert (Qiagen, Venlo, Netherlands). Single-strand cDNAs were generated using the iScriptTM cDNA Synthesis Kit (Bio- Rad, Hercules, CA, USA), and qRT-PCR was performed using the SsoFastTM EvaGreen ${ }^{\circledR}$ supermix kit (BIO-RAD, Hercules, CA, USA) and specific pairs of primers for Emp1 (Fwd 5'-3' GAGACACTGGCCAGAAAAGC; Rev 5' -3' TAAAAGGCAAGGGAATGCAC), S100a10 (Fwd 5' -3' CCTCTGGCTGTGGACAAAAT; Rev 5'-3' CTGCTCACAAGAAGCAGTGG), C3 (Fwd 5' -3' AGCTTCAGGGTCCCAGCTAC; Rev $5^{\prime}-3^{\prime}$ GCTGGAATCTTGATGGAGACGC), and Hif- $1 \alpha$ (Fwd 5'-3' TGCTTACACACAGAAATGGCCC; Rev 5'-3' TATGGCCCGTGCAGTGAAGC). Samples were run in duplicate on 96-well optical PCR plates (Sarstedt AG, Nümbrecht, Germany). Values are expressed as $\Delta \Delta \mathrm{CT}$ relative to housekeeping gene GAPDH (Fwd 5'-3' AACGACCCCTTCATTGAC; Rev 5'-3' TCCACGACATACTCAGCAC) expression.

\subsection{Cell Lysis and Immunoblots}

Astrocytes were lysed in 1\% (v/v) Triton X-100 in $20 \mathrm{mM}$ Tris- $\mathrm{HCl}(\mathrm{pH} 8), 150 \mathrm{mM}$ $\mathrm{NaCl}$ in the presence of Protease Inhibitor Cocktail Set III (Cal BioChem, San Diego, CA, USA), and $0.2 \mathrm{mg} \mathrm{Na}$ orthovanadate $/ \mathrm{mL}$. Proteins were resolved by SDS-PAGE and transferred to nitrocellulose membrane (GE Healthcare Life Sciences, Marlborough, MA, USA) for immunoblotting analysis. Immunoblots were carried out using the following primary antibodies: anti-HSP70 (clone EP1531Y, Abcam, Cambridge, United Kingdom, cod: ab51052, dilution 1:1000), anti-ENOA (clone 3C8, Abnova, Taipei, Taiwan, cod: H00002023M03, dilution 1:1000), anti-PhosphoNF-кBp65 (clone 93H1, Cell Signaling Technology, 
Danvers, MA, USA, cod: 3033, dilution 1:1000), anti-Actin (clone C4, Millipore, Burlington, MA, USA, cod: MAB1501, dilution 1:10,000), anti-NF-kBp65 (clone D14E12, Cell Signaling Technology, Danvers, MA, USA, cod: 8242, dilution 1:1000) and peroxidase-labeled secondary antibodies (anti-rabbit cod: 111-035-144, 1:20,000; and anti-mouse cod:115-035-146, 1:10,000; Jackson ImmunoResearch Laboratories, West Grove, PA, USA). Labeled Abs were detected using the ECL kit (SuperSignal ${ }^{\circledR}$ West Pico Chemiluminescent Substrate, Thermo Scientific, Waltham, MA, USA) and scanned immunoblots were quantified using the ImageJ software.

\subsection{Viability Assay}

Astrocytes were seeded in 6 well-plate $\left(0.5 \times 10^{6}\right.$ astrocytes/well $)$ and treated with $1 \mathrm{mM} \mathrm{H}_{2} \mathrm{O}_{2}$ in serum free medium for $24 \mathrm{~h}$. After, treatment cells were washed two times with PBS and harvested by using trypsin/EDTA solution (Sigma-Merck, Darmstadt, Germany). Cell pellets were resuspended in fresh PBS. The disruption of membrane integrity was determined by adding Propidium Iodide $(50 \mathrm{mg} / \mathrm{mL})$ for $1 \mathrm{~min}$. Samples were acquired on Guava Easy Cyte cytometer (Millipore, Burlington, MA, USA) and the percentage of viable cells (PI-negative) was measured and analyzed with FlowJo software (TreeStar Inc., Ashland, OR, USA).

\subsection{Sample Preparation for Proteomic Analysis}

A total of $40 \times 10^{6}$ astrocytes/sample were seeded in $175 \mathrm{~cm}^{2}$ flasks $\left(7 \times 10^{6}\right.$ cells/flask $)$ and treated or not with IL-17 $(50 \mathrm{ng} / \mathrm{mL})$ in a serum-free medium for $24 \mathrm{~h}$. After the treatments, cells and conditioned media were collected. Astrocyte derived extracellular vesicles (ADEVs) were purified from the cell media by differential ultracentrifugation as described [55]. Briefly, free cells and cellular debris were removed by two centrifugation steps, the first at $300 \times g$ for $10 \mathrm{~min}$ and the second at $100,000 \times g$ for $30 \mathrm{~min}$ at $4{ }^{\circ} \mathrm{C}$. The resulting supernatants were centrifuged at $100,000 \times g$ for $1.30 \mathrm{~h}$ at $4{ }^{\circ} \mathrm{C}$ to pellet ADEVs. The pellets were resuspended in PBS and washed by an additional centrifugation at $100,000 \times g$ for $1.30 \mathrm{~h}$ at $4{ }^{\circ} \mathrm{C}$. Then, the pellets were solubilized in a denaturation solution composed of $8 \mathrm{M}$ urea, $2 \mathrm{M}$ thiourea, $4 \% w / v 3$-[(3-cholamidopropyl) dimethylammonia]-1-propanesulfonate hydrate (CHAPS) and $1 \% w / v$ dithioerythritol (DTE). To prepare cells for proteomic analysis, adherent cells were washed two times with PBS. Cells were collected and washed once in PBS. The resulting pellets were solubilized in a denaturation solution composed of $8 \mathrm{M}$ urea, $2 \mathrm{M}$ thiourea, $4 \%$ $w / v$ 3-[(3-cholamidopropyl) dimethylammonia]-1-propanesulfonate hydrate (CHAPS), and $1 \% w / v$ dithioerythritol (DTE).

Eventually, denaturation solution and traces of bromophenol blue were added to samples carrying the same protein amount in $350 \mu \mathrm{L}$ solution for the analytical run and $700 \mu \mathrm{g}$ on average in $450 \mu \mathrm{L}$ solution for the preparative run.

\subsection{D-Electrophoresis}

2DElectrophoresis (2DE) was performed using the Immobiline polyacrylamide system [56]. Immobilized nonlinear $\mathrm{pH} 3-10$ gradient on strips $18 \mathrm{~cm}$ in length (GE Healthcare, Uppsala, Sweden) were employed in the first dimensional run. Runs were carried out utilizing the EttanTM IPGphorTM Manifold (GE Healthcare, Uppsala, Sweden) at $16{ }^{\circ} \mathrm{C}$ with the following electrical conditions: $30 \mathrm{~V}$ for $8 \mathrm{~h}, 200 \mathrm{~V}$ for $2 \mathrm{~h}$, from $200 \mathrm{~V}$ to $3500 \mathrm{~V}$ in $2 \mathrm{~h}, 3500 \mathrm{~V}$ for $2 \mathrm{~h}$, from $3500 \mathrm{~V}$ to $5000 \mathrm{~V}$ in $2 \mathrm{~h}, 5000 \mathrm{~V}$ for $3 \mathrm{~h}$, from $5000 \mathrm{~V}$ to $8000 \mathrm{~V}$ in $1 \mathrm{~h}, 8000 \mathrm{~V}$ for $3 \mathrm{~h}$, from $8000 \mathrm{~V}$ to $10,000 \mathrm{~V}$ in $1 \mathrm{~h}$, and 10,000 $\mathrm{V}$ for the rest of the run until to reach a total of $90,000 \mathrm{VhT}$. Carrier ampholytes were added to EVs samples at $0.2 \%$ for the analytical runs and at $2 \%$ for the preparative ones. MS-preparative strips were pre-rehydrated with $350 \mu \mathrm{L}$ of samples at $16^{\circ} \mathrm{C}$ for $12 \mathrm{~h}$ at $30 \mathrm{~V}$ and successively, the remaining $100 \mu \mathrm{L}$ were loaded by cup at the cathodic ends, at $16^{\circ} \mathrm{C}$ applying the following voltage conditions: $200 \mathrm{~V}$ for $8 \mathrm{~h}$, from $200 \mathrm{~V}$ to $3500 \mathrm{~V}$ in $2 \mathrm{~h}, 3500 \mathrm{~V}$ for $2 \mathrm{~h}$, from $3500 \mathrm{~V}$ to $5000 \mathrm{~V}$ in $2 \mathrm{~h}, 5000 \mathrm{~V}$ for $3 \mathrm{~h}$, from $5000 \mathrm{~V}$ to $8000 \mathrm{~V}$ in $1 \mathrm{~h}, 8000 \mathrm{~V}$ for $3 \mathrm{~h}$, from $8000 \mathrm{~V}$ to $10,000 \mathrm{~V}$ in $1 \mathrm{~h}$, and $10,000 \mathrm{~V}$ for $10 \mathrm{~h}$ for a total of $90,000 \mathrm{VhT}$. At the end of the first 
dimensional run, strips were washed with deionized water and equilibrated with two buffers: the first composed of $6 \mathrm{M}$ urea, $2 \% w / v$ sodium dodecyl sulphate (SDS), $2 \% w / v$ DTE, 30\% v/v glycerol, and $0.05 \mathrm{M}$ Tris- $\mathrm{HCl} \mathrm{pH} 6.8$ for $12 \mathrm{~min}$; the second one composed of $6 \mathrm{M}$ urea, $2 \% w / v$ SDS, 2.5\% $w / v$ iodoacetamide, 30\% v/v glycerol, $0.05 \mathrm{M}$ Tris- $\mathrm{HCl}$ $\mathrm{pH}$ 6.8, and a trace of bromophenol blue for $5 \mathrm{~min}$. The second dimension was then performed at $40 \mathrm{~mA}$ /gel constant current on 9-16\% SDS polyacrylamide linear gradient gels (size: $18 \times 20 \mathrm{~cm} \times 1.5 \mathrm{~mm}$ ) at $9{ }^{\circ} \mathrm{C}$ [56]. Analytical gels were stained with ammoniacal silver nitrate, while preparative gels underwent a mass spectrometry-compatible silver staining [57]; then, both were digitized with Image Scanner III laser densitometer supplied with the LabScan 6.0 software (GE Healthcare, Uppsala, Sweden). Two-dimensional image analysis was performed using Image Master 2D Platinum 6.0 software (GE Healthcare, Uppsala, Sweden). First, an intra class analysis was performed by matching all gels of the same condition to its "Master gel" (4 gels for WTNS, 3 for KONS, 4 for WTIL17, and 3 for KOIL17) chosen by the user taking into consideration the resolution and the number of spots as criteria; secondly, an inter class analysis was performed by matching all "Master gels" to each other. Gel comparison resulted in quantitative and qualitative protein differences, validated by a statistical analysis.

\subsection{Heatmap and PCA Analysis}

In order to visualize the behavior of the differentially abundant spots in the considered conditions, a heatmap analysis was performed using the \%Volume values of the statistically significative abundant spots. In particular, the clustering of protein spots was performed using Ward's clustering method and Euclidean distance. The above-mentioned analysis and the related figures were obtained by RStudio Desktop 1.1.463 (Integrated Development for RStudio, Inc., Boston, MA, USA, https: / /www.rstudio.com; accessed on 15 December 2020).

Differential spots were also used to perform multivariate analysis by principal component analysis (PCA) simplifying the amount of data (\%V variables) by linear transformation. By PCA, it is possible visualize experimental groups in a two-dimensional plane on the basis of the differential spot patterns. PCA was performed by RStudio Desktop 1.1.463 (Integrated Development for RStudio, Inc., Boston, MA, USA, https: / /www.rstudio.com; accessed on 15 December 2020).

\subsection{MALDI-TOF-TOF MS-Protein Identification}

MS-preparative gels were manually cut to excise electrophoretic spots, which were destained first in a solution of $30 \mathrm{mM}$ potassium ferricyanide and $100 \mathrm{mM}$ sodium sulphate anhydrous, later in $200 \mathrm{mM}$ ammonium bicarbonate and dehydrated in $100 \%$ acetonitrile $(\mathrm{ACN})$. The protein spots were then rehydrated and digested overnight at $37^{\circ} \mathrm{C}$ in trypsin solution. Digested protein solution was placed on MALDI target, dried, covered with matrix solution of $5 \mathrm{mg} / \mathrm{mL} \alpha$-cyano-4-hydroxycinnamic acid (CHCA) in 50\% v/v ACN and $5 \% v / v$ trifluoroacetic acid (TFA) and dried again. MS analysis was then performed with UltrafleXtreme ${ }^{\mathrm{TM}}$ MALDI-ToF/ToF instrument equipped with a $200 \mathrm{~Hz}$ smartbeam ${ }^{\mathrm{TM}}$ I laser in the positive reflector mode according to defined parameters: $80 \mathrm{~ns}$ of delay; ion source 1: $25 \mathrm{kV}$; ion source 2: $21.75 \mathrm{kV}$; lens voltage: $9.50 \mathrm{kV}$; reflector voltage: $26.30 \mathrm{kV}$; and reflector 2 voltage: $14.00 \mathrm{kV}$. The applied laser wavelength and frequency were $353 \mathrm{~nm}$ and $100 \mathrm{~Hz}$, respectively, and the percentage was set to $46 \%$. Final mass spectra were produced by averaging 1500 laser shots targeting five different positions within the spot. Spectra were acquired automatically and the Flex Analysis software version 3.0 (Bruker) was used for their analysis and for assigning the peaks. The applied software generated a list of peaks up to 200, using a signal-to-noise ratio of 3 as threshold for peak acceptance. Recorded spectra were calibrated using peptides arising from trypsin autoproteolysis as internal standard. The resulting mass lists were filtered for contaminant removal: mass matrix-related ions, trypsin autolysis, and keratin peaks. PMF search was performed using MASCOT (Matrix Science Ltd., London, UK, http:/ / www.matrixscience.com; accessed on 
1 May 2021) setting up the following search parameters: Mus musculus as taxonomy, SwissProt/TrEMBL as databases, $100 \mathrm{ppm}$ as mass tolerance, one admissible missed cleavage site, carbamidomethylation (iodoacetamide alkylation) of cysteine as fixed modification, and oxidation of methionine as a variable modification.

\subsection{Network and Pathway Analysis}

Network and pathway analysis were performed submitting the accession number of the identified proteins to the MetaCore 6.8 network building tool (Clarivate Analytics, Philadelphia, PA, USA). This software shows a network of protein interactions, graphically represented by "nodes" (proteins) and "arches" (interactions), by the "shortest-path" algorithm. This algorithm builds a hypothetical network connecting two experimental proteins directly or indirectly using one MetaCore database protein, based on information from scientific literature data and annotated databases of protein interactions and metabolic reactions. The relevant pathway maps were then prioritized according to their statistical significance $(p \leq 0.001)$.

\subsection{Statistical Analysis}

For proteomic data, parametric Student's $t$ test was used to compare the percentage of relative volume $(\% \mathrm{~V})$ of the $2 \mathrm{DE}$ protein spots among the groups. Particularly, only differentially abundant spots with a $p$-value $\leq 0.05$ and at least two-fold change in the ratio of the $\% \mathrm{~V}$ means were considered statistically significant. Two-way ANOVA with post hoc Bonferroni's test was used for all the other experiments in which multiple groups were compared. An unpaired $t$-test was used to determine the statistical significance of differences between two groups. GraphPad Prism Software (Version 8.4.2) was used for statistical analyses. A $p<0.05$ was considered as statistically significant.

Supplementary Materials: The following are available online at https:/ / www.mdpi.com/article/10 $.3390 /$ ijms22157933/s1.

Author Contributions: Conceptualization, C.L., C.T.B. and C.U; methodology, T.M., E.S., D.D.T., F.D.G., S.A., L.B., C.L., C.T.B. and C.U.; validation, T.M., D.D.T. and E.S.; formal analysis, T.M., E.S., D.D.T., F.D.G., S.A., L.B., C.L., C.T.B. and C.U; investigation, T.M., E.S., D.D.T., F.D.G., S.A., C.L. and C.U.; resources, C.T.B. and L.B.; writing-original draft preparation, T.M., E.S., D.D.T., L.B., C.L., C.T.B. and C.U.; writing-review and editing, T.M., E.S., D.D.T., L.B., C.L., C.T.B. and C.U.; supervision, C.L., C.T.B. and C.U.; funding acquisition, C.T.B. All authors have read and agreed to the published version of the manuscript.

Funding: This research was funded by Fondazione Italiana Sclerosi Multipla grant \#2014/R/3 to C.T.B.

Institutional Review Board Statement: The use of animals in this study was conducted according to the guidelines of the 2010/63/EU Directive and approved by the Italian Ministry of Health.

Data Availability Statement: The data generated in this study are available on request from the corresponding authors.

Conflicts of Interest: The authors declare no conflict of interest.

\section{References}

1. Verkhratsky, A.; Nedergaard, M. Physiology of astroglia. Physiol. Rev. 2018, 98, 239-389. [CrossRef] [PubMed]

2. Verkhratsky, A.; Matteoli, M.; Parpura, V.; Mothet, J.P.; Zorec, R. Astrocytes as secretory cells of the central nervous system: Idiosyncrasies of vesicular secretion. EMBO J. 2016, 35, 239-257. [CrossRef]

3. Keaney, J.; Campbell, M. The dynamic blood-brain barrier. FEBS J. 2015, 282, 4067-4079. [CrossRef] [PubMed]

4. Vardjan, N.; Parpura, V.; Verkhratsky, A.; Zorec, R. Gliocrine system: Astroglia as secretory cells of the CNS. Adv. Exp. Med. Biol. 2019, 1175, 93-115. [PubMed]

5. Escartin, C.; Guillemaud, O.; Carrillo-de Sauvage, M.A. Questions and (some) answers on reactive astrocytes. Glia 2019, 67, 2221-2247. [CrossRef] [PubMed]

6. Liddelow, S.A.; Guttenplan, K.A.; Clarke, L.E.; Bennett, F.C.; Bohlen, C.J.; Schirmer, L.; Bennett, M.L.; Munch, A.E.; Chung, W.S.; Peterson, T.C.; et al. Neurotoxic reactive astrocytes are induced by activated microglia. Nature 2017, 541, 481-487. [CrossRef] 
7. Baecher-Allan, C.; Kaskow, B.J.; Weiner, H.L. Multiple sclerosis: Mechanisms and immunotherapy. Neuron 2018, 97, 742-768. [CrossRef]

8. Colonna, M.; Butovsky, O. Microglia function in the central nervous system during health and neurodegeneration. Annu. Rev. Immunol. 2017, 35, 441-468. [CrossRef]

9. Brambilla, R. The contribution of astrocytes to the neuroinflammatory response in multiple sclerosis and experimental autoimmune encephalomyelitis. Acta Neuropathol. 2019, 137, 757-783. [CrossRef] [PubMed]

10. Gorshkov, K.; Aguisanda, F.; Thorne, N.; Zheng, W. Astrocytes as targets for drug discovery. Drug Discov. Today 2018, 23, 673-680. [CrossRef]

11. Rodriques, S.G.; Stickels, R.R.; Goeva, A.; Martin, C.A.; Murray, E.; Vanderburg, C.R.; Welch, J.; Chen, L.M.; Chen, F.; Macosko, E.Z Slide-seq: A scalable technology for measuring genome-wide expression at high spatial resolution. Science 2019, 363, 1463-1467. [CrossRef] [PubMed]

12. Svensson, V.; Vento-Tormo, R.; Teichmann, S.A. Exponential scaling of single-cell RNA-seq in the past decade. Nat. Protoc. 2018, 13, 599-604. [CrossRef] [PubMed]

13. Wheeler, M.A.; Clark, I.C.; Tjon, E.C.; Li, Z.; Zandee, S.E.J.; Couturier, C.P.; Watson, B.R.; Scalisi, G.; Alkwai, S.; Rothhammer, V.; et al. MAFG-driven astrocytes promote CNS inflammation. Nature 2020, 578, 593-599. [CrossRef]

14. Savino, M.T.; Ortensi, B.; Ferro, M.; Ulivieri, C.; Fanigliulo, D.; Paccagnini, E.; Lazzi, S.; Osti, D.; Pelicci, G.; Baldari, C.T. Rai acts as a negative regulator of autoimmunity by inhibiting antigen receptor signaling and lymphocyte activation. J. Immunol. 2009, 182, 301-308. [CrossRef] [PubMed]

15. Savino, M.T.; Ulivieri, C.; Emmi, G.; Prisco, D.; De Falco, G.; Ortensi, B.; Beccastrini, E.; Emmi, L.; Pelicci, G.; D’Elios, M.M.; et al. The Shc family protein adaptor, Rai, acts as a negative regulator of Th17 and Th1 cell development. J. Leukoc. Biol. 2013, 93, 549-559. [CrossRef]

16. Ulivieri, C.; Savino, M.T.; Luccarini, I.; Fanigliulo, E.; Aldinucci, A.; Bonechi, E.; Benagiano, M.; Ortensi, B.; Pelicci, G.; D’Elios, M.M.; et al. The adaptor protein Rai/ShcC promotes astrocyte-dependent inflammation during experimental autoimmune encephalomyelitis. J. Immunol. 2016, 197, 480-490. [CrossRef] [PubMed]

17. Ulivieri, C.; De Tommaso, D.; Finetti, F.; Ortensi, B.; Pelicci, G.; D’Elios, M.M.; Ballerini, C.; Baldari, C.T. A T cell suppressive circuitry mediated by CD39 and regulated by ShcC/Rai is induced in astrocytes by encephalitogenic T cells. Front. Immunol. 2019, 10, 1041. [CrossRef]

18. Linnerbauer, M.; Wheeler, M.A.; Quintana, F.J. Astrocyte crosstalk in CNS inflammation. Neuron 2020, 108, 608-622. [CrossRef]

19. Chen, J.; Liu, X.; Zhong, Y. Interleukin-17A: The key cytokine in neurodegenerative diseases. Front. Aging Neurosci. 2020, 12, 566922. [CrossRef] [PubMed]

20. Haque, A.; Ray, S.K.; Cox, A.; Banik, N.L. Neuron specific enolase: A promising therapeutic target in acute spinal cord injury. Metab. Brain Dis. 2016, 31, 487-495. [CrossRef]

21. Feinstein, D.L.; Galea, E.; Aquino, A.; Li, G.C.; Xu, H.; Reis, D.J. Heat shock protein 70 suppresses astroglial-inducible nitric-oxide synthase expression by decreasing NFkappaB activation. J. Biol. Chem. 1996, 271, 17724-17732. [CrossRef] [PubMed]

22. Kim, J.Y.; Barua, S.; Huang, M.Y.; Park, J.; Yenari, M.A.; Lee, J.E. Heat shock protein 70 (HSP70) induction: Chaperonotherapy for neuroprotection after brain injury. Cells 2020, 9, 2020. [CrossRef]

23. Cummins, E.P.; Berra, E.; Comerford, K.M.; Ginouves, A.; Fitzgerald, K.T.; Seeballuck, F.; Godson, C.; Nielsen, J.E.; Moynagh, P.; Pouyssegur, J.; et al. Prolyl hydroxylase-1 negatively regulates IкB kinase- $\beta$, giving insight into hypoxia-induced NFkB activity. Proc. Natl. Acad. Sci. USA 2006, 103, 18154-18159. [CrossRef] [PubMed]

24. Lee, M.; Wang, C.; Jin, S.W.; Labrecque, M.P.; Beischlag, T.V.; Brockman, M.A.; Choy, J.C. Expression of human inducible nitric oxide synthase in response to cytokines is regulated by hypoxia-inducible factor-1. Free Radic. Biol. Med. 2019, 130, $278-287$. [CrossRef]

25. Semenza, G.L. Hypoxia-inducible factor 1: Control of oxygen homeostasis in health and disease. Pediatr. Res. 2001, 49, 614-617. [CrossRef] [PubMed]

26. Haider, L.; Fisher, M.T.; Frischer, J.M.; Bauer, J.; Höftberger, R.; Botond, G.; Esterbauer, H.; Binder, C.J.; Witztum, J.L.; Lassmann, H. Oxidative damage in multiple sclerosis lesions. Brain 2011, 134, 1914-1924. [CrossRef]

27. Nikic, I.; Merkler, D.; Sorbara, C.; Brinkoetter, M.; Kreutzfeld, M.; Bareyre, F.M.; Bruck, W.; Bishop, D.; Misgeld, T.; Kerschensteiner, M. A reversible form of axon damage in experimental autoimmune encephalomyelitis and multiple sclerosis. Nat. Med. 2011, 17, 495-499. [CrossRef] [PubMed]

28. Lassmann, H. Pathogenic mechanisms associated with different clinical courses of multiple sclerosis. Front. Immunol. 2019, 9, 3116. [CrossRef]

29. Lassmann, H. Multiple sclerosis pathology. Cold Spring Harb. Perspect. Med. 2018, 8, a028936. [CrossRef]

30. Magliozzi, R.; Howell, O.; Vora, A.; Serafini, B.; Nicholas, R.; Puopolo, M.; Reynolds, R.; Aloisi, F. Meningeal B-cell follicles in secondary progressive multiple sclerosis associate with early onset of disease and severe cortical pathology. Brain 2007, 130, 1089-1104. [CrossRef]

31. Ponath, G.; Park, C.; Pitt, D. The role of astrocytes in multiple sclerosis. Front. Immunol. 2018, 9, 217. [CrossRef]

32. Mansilla, M.J.; Montalban, X.; Espejo, C. Heat shock protein 70: Roles in multiple sclerosis. Mol. Med. 2012, 18, 1018-1028. [CrossRef] 
33. Block, M.L.; Zecca, L.; Hong, J.S. Microglia-mediated neurotoxicity: Uncovering the molecular mechanisms. Nat. Rev. Neurosci. 2007, 8, 57-69. [CrossRef]

34. Kim, J.Y.; Kim, J.W.; Yenari, M.A. Heat shock protein signaling in brain ischemia and injury. Neurosci. Lett. 2020, 715, 134642. [CrossRef]

35. Chen, Y.; Gaber, T. Hypoxia/HIF modulates immune responses. Biomedicines 2021, 9, 260. [CrossRef]

36. Shan, K.; Pang, R.; Zhao, C.; Liu, X.; Gao, W.; Zhang, J.; Zhao, D.; Wang, Y.; Qiu, W. IL-17-triggered downregulation of miR-497 results in high HIF-1 $\alpha$ expression and consequent IL-1 $\beta$ and IL-6 production by astrocytes in EAE mice. Cell Mol. Immunol. 2017, 14, 909-923. [CrossRef] [PubMed]

37. Criscuoli, M.; Ulivieri, C.; Filippi, I.; Monaci, S.; Guerrini, G.; Crifò, B.; De Tommaso, D.; Pelicci, G.; Baldari, C.T.; Taylor, C.T.; et al. The Shc protein Rai enhances T-cell survival under hypoxia. J. Cell Physiol. 2020, 235, 8058-8070. [CrossRef] [PubMed]

38. Nzou, G.; Wicks, R.T.; VanOstrand, N.R.; Mekky, G.A.; Seale, S.A.; El-Taibany, A.; Wicks, E.E.; Nechtman, C.M.; Marrotte, E.J.; Makani, V.S.; et al. Multicellular 3D neurovascular unit model for assessing hypoxia and neuroinflammation induced blood-brain barrier dysfunction. Sci. Rep. 2020, 10, 9766. [CrossRef] [PubMed]

39. Rajda, C.; Pukoli, D.; Bende, Z.; Majlath, Z.; Vecsei, L. Excitotoxins, mitochondrial and redox disturbances in multiple sclerosis. Int. J. Mol. Sci. 2017, 18, 353. [CrossRef]

40. Lizarraga-Valderrama, L.R.; Sheridan, G.K. Extracellular vesicles and intercellular communication in the central nervous system. FEBS Lett. 2021. [CrossRef]

41. Pascua-Maestro, R.; Gonzalez, E.; Lillo, C.; Ganfornina, M.D.; Falcon-Perez, J.M.; Sanchez, D. Extracellular vesicles secreted by astroglial cells transport Apolipoprotein D to neurons and mediate neuronal survival upon oxidative stress. Front. Cell Neurosci. 2019, 12, 526. [CrossRef] [PubMed]

42. Wang, S.; Cesca, F.; Loers, G.; Schweizer, M.; Buck, F.; Benfenati, F.; Schachner, M.; Kleene, R. Synapsin I is an oligomannosecarrying glycoprotein, acts as an oligomannose-binding lectin, and promotes neurite outgrowth and neuronal survival when released via glia-derived exosomes. J. Neurosci. 2011, 31, 7275-7290. [CrossRef]

43. Chaudhuri, A.D.; Dasgheyb, R.M.; DeVine, L.R.; Bi, H.; Cole, R.N.; Haughey, N.J. Stimulus-dependent modifications in astrocytederived extracellular vesicle cargo regulate neuronal excitability. Glia 2020, 68, 128-144. [CrossRef] [PubMed]

44. Dolcetti, E.; Bruno, A.; Guadalupi, L.; Rizzo, F.R.; Musella, A.; Gentile, A.; De Vito, F.; Caioli, S.; Bullitta, S.; Fresegna, D.; et al. Emerging role of extracellular vesicles in the pathophysiology of multiple sclerosis. Int. J. Mol. Sci. 2020, 21, 7336. [CrossRef]

45. Hampe, L.; Radjainia, M.; Xu, C.; Harris, P.W.R.; Bashiri, G.; Goldstone, D.C.; Brimble, M.A.; Wang, Y.; Mitra, A.K. Regulation and quality control of Adiponectin assembly by endoplasmic reticulum chaperone ERp44. J. Biol. Chem. 2015, 290, 18111-18123. [CrossRef]

46. Zhang, K.; Guo, Y.; Ge, Z.; Zhang, Z.; Da, Y.; Li, W.; Zhang, Z.; Xue, Z.; Li, Y.; Ren, Y.; et al. Adiponectin suppresses T Helper 17 cell differentiation and limits autoimmune cns inflammation via the SIRT1/PPAR $\gamma /$ ROR $\gamma$ t pathway. Mol. Neurobiol. 2017, 54, 4908-4920. [CrossRef]

47. Nicolas, S.; Cazareth, J.; Zarif, H.; Guyon, A.; Heurteaux, C.; Chabry, J.; Petit-Paitel, A. Globular adiponectin limits microglia pro-inflammatory phenotype through an AdipoR1/NF-kB signaling pathway. Front. Cell Neurosci. 2017, 11, 352. [CrossRef] [PubMed]

48. Vouyiouklis, D.A.; Brophy, P.J. Microtubule-associated proteins in developing oligodendrocytes: Transient expression of a MAP2c isoform in oligodendrocyte precursors. J. Neurosci. Res. 1995, 42, 803-817. [CrossRef]

49. Luoma, A.M.; Kuo, F.; Cakici, O.; Crowther, M.N.; Denninger, A.R.; Avila, R.L.; Brites, P.; Kirschner, D.A. Plasmalogen phospholipids protect internodal myelin from oxidative damage. Free Radic. Biol. Med. 2015, 84, 296-310. [CrossRef]

50. Sagi, O.; Budovsky, A.; Wolfson, M.; Fraifeld, V.E. ShcC proteins: Brain aging and beyond. Ageing Res. Rev. 2015, 19, 34-42. [CrossRef] [PubMed]

51. Troglio, F.; Echart, C.; Gobbi, A.; Pawson, T.; Pelicci, P.G.; De Simoni, M.G.; Pelicci, G. The Rai (ShcC) adaptor protein regulates the neuronal stress response and protects against cerebral ischemia. Proc. Natl. Acad. Sci. USA 2004, 101, 15476-15481. [CrossRef]

52. Sakai, R.; Henderson, J.T.; O’Bryan, J.P.; Elia, A.J.; Saxton, T.M.; Pawson, T. The mammalian ShcB and ShcC phosphotyrosine docking proteins function in the maturation of sensory and sympathetic neurons. Neuron 2000, 28, 819-833. [CrossRef]

53. Aloisi, F.; Ria, F.; Penna, G.; Adorini, L. Microglia are more efficient than astrocytes in antigen processing and in Th1 but not Th2 cell activation. J. Immunol. 1998, 160, 4671-4680.

54. Colombo, E.; Cordiglieri, C.; Melli, G.; Newcombe, J.; Krumbholz, M.; Parada, L.F.; Medico, E.; Hohlfeld, R.; Meinl, E.; Farina, C. Stimulation of the neurotrophin receptor TrkB on astrocytes drives nitric oxide production and neurodegeneration. J. Exp. Med. 2012, 209, 521-535. [CrossRef] [PubMed]

55. Théry, C.; Amigorena, S.; Raposo, G.; Clayton, A. Isolation and characterization of exosomes from cell culture supernatants and biological fluids. Curr. Protoc. Cell Biol. 2006, 3, 3-22. [CrossRef] [PubMed]

56. Bjellqvist, B.; Pasquali, C.; Ravier, F.; Sanchez, J.C.; Hochstrasser, D. A nonlinear wide-range immobilized pH gradient for two-dimensional electrophoresis and its definition in a relevant pH scale. Electrophoresis 1993, 14, 1357-1365. [CrossRef]

57. Hochstrasser, D.F.; Patchornik, A.; Merril, C.R. Development of polyacrylamide gels that improve the separation of proteins and their detection by silver staining. Anal. Biochem. 1988, 173, 412-423. [CrossRef] 